\title{
PD-1 signaling affects cristae morphology and leads to mitochondrial dysfunction in human $\mathrm{CD} 8^{+} \mathrm{T}$ lymphocytes
}

Jesús Ogando ${ }^{1}$, María Eugenia Sáez ${ }^{2}$, Javier Santos ${ }^{1}$, Cristina Nuevo-Tapioles ${ }^{3}$, Marta Gut ${ }^{4,5}$, Anna Esteve-Codina ${ }^{4}$, Simon Heath ${ }^{4,5}$, Antonio González-Pérez ${ }^{2}$, José M. Cuezva ${ }^{3}$, Rosa Ana Lacalle ${ }^{1}$ and Santos Mañes ${ }^{1 *}$ (D)

\begin{abstract}
Background: Binding of the programmed death-1 (PD-1) receptor to its ligands (PD-L1/2) transduces inhibitory signals that promote exhaustion of activated T cells. Blockade of the PD-1 pathway is widely used for cancer treatment, yet the inhibitory signals transduced by PD-1 in T cells remain elusive.

Methods: Expression profiles of human $\mathrm{CD}^{+} \mathrm{T}$ cells in resting, activated (CD3 + CD28) and PD-1-stimulated cells $(C D 3+C D 28+$ PD-L1-FC) conditions were evaluated by RNA-seq. Bioinformatic analyses were used to identify signaling pathways differentially regulated in PD-1-stimulated cells. Metabolic analyses were performed with SeaHorse technology, and mitochondrial ultrastructure was determined by transmission electron microscopy. PD-1regulated mitochondrial genes were silenced using short-hairpin RNA in primary cells. Blue native gel electrophoresis was used to determine respiratory supercomplex assembly.

Results: PD-1 engagement in human $\mathrm{CD}^{+} \mathrm{T}$ cells triggers a specific, progressive genetic program different from that found in resting cells. Gene ontology identified metabolic processes, including glycolysis and oxidative phosphorylation (OXPHOS), as the main pathways targeted by PD-1. We observed severe functional and structural alterations in the mitochondria of PD-1-stimulated cells, including a reduction in the number and length of mitochondrial cristae. These cristae alterations were associated with reduced expression of CHCHD3 and CHCHD10, two proteins that form part of the mitochondrial contact site and cristae organizing system (MICOS). Although PD1-stimulated cells showed severe cristae alterations, assembly of respiratory supercomplexes was unexpectedly greater in these cells than in activated T cells. CHCHD3 silencing in primary $\mathrm{CD} 8^{+} \mathrm{T}$ cells recapitulated some effects induced by PD-1 stimulation, including reduced mitochondrial polarization and interferon- $\gamma$ production following $T$ cell activation with anti-CD3 and -CD28 activating antibodies.
\end{abstract}

Conclusions: Our results suggest that mitochondria are the main targets of PD-1 inhibitory activity. PD-1 reprograms $\mathrm{CD}^{+} \mathrm{T}$ cell metabolism for efficient use of fatty acid oxidation; this mitochondrial phenotype might explain the long-lived phenotype of PD-1-engaged T cells.

Keywords: PD-1, CD8, RNA-seq, Metabolism, Mitochondrion, Cristae, MICOS

\footnotetext{
*Correspondence: smanes@cnb.csic.es

'Department of Immunology and Oncology, Centro Nacional de

Biotecnología (CNB/CSIC), Madrid, Spain

Full list of author information is available at the end of the article
}

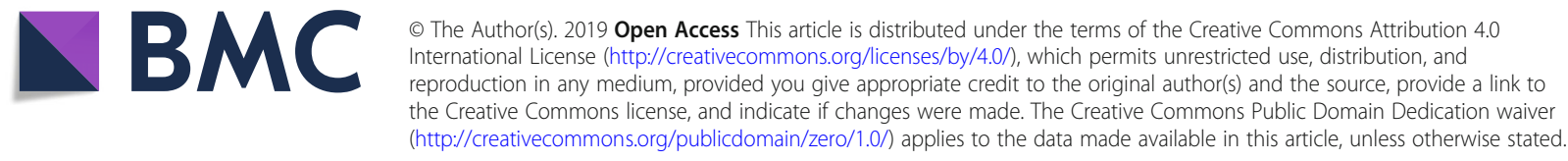




\section{Background}

Programmed death-1 (PD-1; CD279) acts as a negative regulator of the immune response at the effector phase. PD-1 transmits inhibitory signals in $\mathrm{T}$ cells after interaction with its ligands, PD-L1 (B7-H1; CD274) and PD-L2 (B7-DC; CD273). The PD-1/PD-L1/2 system is central to the maintenance of peripheral tolerance by preventing the activation of autoreactive $\mathrm{T}$ cells that escape from central tolerance-mediated deletion [1]. High PD-L1/2 levels in non-hematopoietic tissues are associated with suppression of tissue-reactive T cells [2].

Chronic exposure to antigen, as occurs in some infections and most cancers, results in progressive loss of antigen-specific $\mathrm{T}$ cell effector capacity, a phenomenon termed exhaustion [3]. Exhausted T cells are characterized by the expression of inhibitory receptors including PD-1. An inverse correlation was reported between $\mathrm{T}$ cell function and PD-1 expression levels [4], which has been exploited therapeutically. Immunotherapy based on antibodies that neutralize PD-1 or its ligand PD-L1 effectively restores exhausted T cell-mediated anti-tumor responses in a variety of advanced cancers in humans, with durable effects and high efficacy compared with standard cancer treatments [5].

Despite extensive clinical use of PD-1-based therapeutics, little is known of the mechanisms that underlie PD1-induced $\mathrm{T}$ cell exhaustion. PD-1-mediated inhibition relies on the immunoreceptor tyrosine-based inhibition motif (ITIM) and the immunoreceptor tyrosine-based switch motif (ITSM) in the PD-1 cytoplasmic tail [6]. PD-1 binding to its ligands leads to tyrosine phosphorylation of a residue in its ITSM, which acts as a docking site for recruitment of the Src homology region 2 domain-containing phosphatase-2 (SHP-2, encoded by the PTPN11 gene). PD-1 can also recruit the tyrosine phosphatase SHP-1 (encoded by the PTPN6 gene), but only SHP-2 colocalizes with PD-1 and the TCR at the immune synapse [7]. SHP-2 recruitment to activated PD-1 is postulated to cause dephosphorylation of TCRinduced signaling intermediates such as ZAP70 [6, 7]. Regardless of its tyrosine phosphatase activity, SHP-2 positively regulates various signaling cascades [8, 9], including extracellular signal-regulated kinase (ERK) activation following TCR triggering [10, 11]. A recent report showed that SHP-2 is totally dispensable for PD-1 signaling and $\mathrm{T}$ cell exhaustion in vivo [12].

PD-1 also targets metabolic reprogramming in $\mathrm{CD}_{4}^{+}$ and $\mathrm{CD}^{+} \mathrm{T}$ cells. Resting and memory $\mathrm{T}$ cells typically use an oxidative metabolic program (OXPHOS) characterized by increased mitochondrial fatty acid oxidation and spare respiratory capacity (SRC) $[13,14]$. In contrast, effector $\mathrm{T}$ cells rewire their metabolism to potentiate aerobic glycolysis, which triggers proliferation and expression of effector cytokines such as interferon- gamma (IFNY). Mitochondrial function and integrity are nonetheless critical for both effector and memory phases of $\mathrm{T}$ cell differentiation [15].

In vitro studies show that PD-1 stimulation reduces the extracellular acidification rate (ECAR) as well as basal and stimulated $\mathrm{O}_{2}$ consumption rates (OCR), which indicates that PD-1 engagement dysregulates both glycolytic and mitochondrial energetics in activated $\mathrm{T}$ cells [16]. Similar metabolic alterations are observed in vivo in exhausted virus-reactive and tumor-infiltrating lymphocytes (TIL) [17-19]. Whereas PD-1-mediated suppression of glycolysis might be caused by abrogation of the AKT and mTOR pathways downstream of the TCR $[16,20]$, the mechanisms by which PD-1 affects mitochondria are mainly unknown.

To investigate the PD-1-elicited signaling pathways that cause $\mathrm{T}$ cell dysregulation, we analyzed the expression profiling of human $\mathrm{CD}^{+} \mathrm{T}$ cells in conditions that mimic simultaneous engagement of PD-1 and the TCR/ CD3 complex. We show here that PD-1 engagement triggers a specific, time-dependent genetic program different from that in resting cells. This finding suggests that in addition to blocking TCR-mediated signals, PD-1 can generate specific signaling pathways that dysregulate $\mathrm{T}$ cell function. We provide a mechanistic framework that explains the reduction in the number and length of mitochondrial cristae in PD-1-engaged cells, which involves reduced expression of two proteins that form part of the MICOS complex.

\section{Methods}

For a more detailed description, see Additional file 1.

\section{Cell culture and $\mathrm{T}$ cell activation}

Human embryonic kidney (HEK)-293 T cells (ATCC) were cultured in DMEM (BioWest). Peripheral blood mononuclear cells (PBMC) were obtained from buffy coats from healthy donors (Centro de Transfusiones of the Comunidad de Madrid, Spain), using Ficoll density gradients. $\mathrm{CD}^{+} \mathrm{T}$ cells were isolated by negative selection (EasySep human $\mathrm{CD}^{+} \mathrm{T}$ cell, Stem Cell Technologies; $86-95.5 \%$ purity), and cultured in RPMI-1640 medium (BioWest).

For activation, $\mathrm{CD}^{+} \mathrm{T}$ cells were incubated (1:3.5 ratio) with tosyl-activated magnetic beads (Dynabeads M-450; Thermo Scientific) coated with $8 \%$ anti-CD3 (HIT3a, BD Biosciences), 10\% anti-CD28 (CD28.2, BioLegend), and $82 \%$ control $\operatorname{IgG}_{1}\left(\mathrm{~T}_{\mathrm{ACT}}\right)$, or with antiCD3, anti-CD28, and 82\% PD-L1-Fc chimeric protein (R\&D Systems) $\left(\mathrm{T}_{\mathrm{ACT}+\mathrm{PD} 1}\right) ; \mathrm{IgG}_{1}$-coated beads were used as control $\left(\mathrm{T}_{\mathrm{CTRL}}\right)$. In some experiments, PD-L1-Fc was used at $16.4,3.3 \%$ or $0.66 \%$. In some experiments,

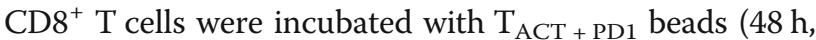
$37^{\circ} \mathrm{C}$ ), which were mechanically released, removed with 
a magnet, and the cells restimulated with $\mathrm{T}_{\mathrm{ACT}}$ or $\mathrm{T}_{\mathrm{CTRL}}$ beads $\left(48 \mathrm{~h}, 37^{\circ} \mathrm{C}\right)$. As positive control, naïve $\mathrm{CD} 8^{+} \mathrm{T}$ cells were incubated $\left(48 \mathrm{~h}, 37^{\circ} \mathrm{C}\right)$ with plate-bound antiCD3 $(5 \mu \mathrm{g} / \mathrm{ml}$; UCHT1, BD Biosciences) and soluble anti-CD28 $(2 \mu \mathrm{g} / \mathrm{ml})$ antibodies.

$\mathrm{T}$ cell activation was confirmed by FACS (Cytomics FC500 or Gallios cytometers; Beckman Coulter) using anti-CD25-PE (B1.49.9, Beckman-Coulter), -CD279APC (MIH4, eBioscience), -CD69-PCy5 (TP1.553, Inmunotech), and -CD8-FITC (B9.11, Beckman-Coulter) antibodies. IFN $\gamma$ was detected by intracellular staining using anti-IFNY-PE (B27, Pharmingen) antibody in permeabilized cells (Beckman-Coulter) pretreated with brefeldin A $\left(10 \mu \mathrm{g} / \mathrm{ml}, 4 \mathrm{~h}, 37^{\circ} \mathrm{C}\right.$; eBioscience). Dead cells were detected with propidium iodide $(2.5 \mu \mathrm{g} / \mathrm{test}, 1 \mathrm{~min})$, or the LIVE/DEAD stain kit (Invitrogen). Appropriate isotypes were used as negative controls. Data were analyzed using Kaluza and FlowJo software.

$\mathrm{hCD}^{+} \mathrm{T}$ cell proliferation was determined by [methyl- ${ }^{3} \mathrm{H}$ ] thymidine $(1 \mu \mathrm{Ci} /$ well; Perkin Elmer $)$ incorporation into DNA, in a 1450 Microbeta liquid scintillation counter (Perkin Elmer).

\section{RNA-seq analysis}

The RNA-seq libraries were prepared using an Illumina TruSeq Stranded Total RNA Sample Preparation kit (Illumina). Library size and quality was assessed in an Agilent DNA 7500 Bioanalyzer assay (Agilent). Each library was sequenced using TruSeq SBS Kit v3-HS, in paired end mode with read length $2 \times 76 \mathrm{bp}$. On average, we generated 36 million paired-end reads for each sample in a fraction of a sequencing lane on HiSeq2000 (Illumina). Image analysis, base calling, and quality scoring of the run were processed by Real Time Analysis (RTA 1.13.48) software, followed by generation of FASTQ sequence files by CASAVA 1.8.

RNA-seq reads were aligned with the human reference genome (gencode v19) using the GEMtools RNA-seq pipeline v1.7 (http://gemtools.github.io), which is based on the GEM mapper [21]. Expression quantification at the gene level was calculated with Flux (http://sammeth. net/confluence/display/FLUX/Home). RNA-seq data were analyzed using the DESeq2 $\mathrm{R}$ Bioconductor package [22]. Raw counts of sequencing reads were normalized to the effective library size. Real-time quantitative PCR (qPCR) was performed in an ABI PRISM7900HT system (Applied Biosystems) with indicated primers (Additional file 2: Table S1).

A likelihood ratio test (LRT) was used to test for differences over multiple time points. This test compares a full model, including an interaction term class:time, with a reduced model without the interaction term; this permits to determine whether PD-1 treatment induces change of a specific gene at any point after time 0 . This class-specific effect is measured as a $p$ value for interaction ( $\mathrm{p}_{\text {inter }}$ ) and $\mathrm{FC}$ values for $\mathrm{T}_{\mathrm{ACT}+\mathrm{PD} 1}$ vs. $\mathrm{T}_{\mathrm{ACT}}$ cells at each time point. Genes with a significant $p_{\text {inter }}$ were analyzed by STEM (Short Time-series Expression Miner) software [23] for cluster analysis and integration with the Gene Ontology (GO) database (http://geneonto $\operatorname{logy}$. org/). These genes were analyzed for enrichment in KEGG signaling pathways using the online tool Webgestalt (http://www.webgestalt.org). Genes involved in metabolic pathways (KEGG hsa011000) were further explored for known interactions using Cytoescape (http://www.cytoscape.org/). GO enrichment analysis was performed using BINGO. GO categories were summarized and visualized using ClueGO or REVIGO.

\section{Metabolic assays}

Cellular oxygen consumption (OCR) and extracellular acidification rates (ECAR) were determined in Seahorse XF Base Medium supplemented with $25 \mathrm{mM}$ glucose (Sigma-Aldrich), $2 \mathrm{mM} \mathrm{L-glutamine} \mathrm{and} 1 \mathrm{mM}$ sodium pyruvate (both from BioWest) using the XF cell Mito Stress Kit (SeaHorse Bioscience), in an XF24 Extracellular Flux Analyzer (SeaHorse Bioscience; Agilent Technologies). Fatty acid oxidation (FAO) was determined in Krebs-Henseleit buffer (KHB) supplemented with 0.5 $\mathrm{mM}$ carnitine (Sigma-Aldrich) and $2.5 \mathrm{mM}$ glucose, using palmitate as substrate, in the Agilent Seahorse XF96 Extracellular Flux Analyzer.

Lactate levels were determined enzymatically in extracts from $\mathrm{T}_{\mathrm{CTRL}}, \mathrm{T}_{\mathrm{ACT}}$ and $\mathrm{T}_{\mathrm{ACT}+\mathrm{PD} 1}$ cells after $48 \mathrm{~h}$ stimulation, using a fluorometric lactate assay kit (Cell Biolabs) according to supplier's protocol; fluorescence was quantified in a Filter Max F5 microplate reader (Molecular Devices) at 530/590 nm excitation/emission. A lactate standard curve was generated in all assays and used to extrapolate relative fluorescent units (RFU) measured in the samples.

\section{Blue native and immunoblot analyses}

Equal amounts of Triton X-100-based cells lysed were analyzed by SDS-PAGE analysis and immunoblotted with specific antibodies (see Additional file 1) [24]. For blue native analyses, we obtained a mitochondria-enriched fraction by cell lysis with hypotonic buffer and homogenization with a polypropylene pestle homogenizer. Nuclei and unbroken cells were removed, and mitochondria obtained by centrifugation $(12,000 \times g)$ from the cytosolic fraction. The enriched mitochondrial fraction was suspended in $50 \mathrm{mM}$ Tris- $\mathrm{HCl} \mathrm{pH} 7.0$ containing $1 \mathrm{M}$ 6-aminohexanoic acid, lysed in $10 \%$ digitonin at $4 \mathrm{~g} / \mathrm{g}$ mitochondrial proteins, and mitochondrial proteins fractionated in blue native gels. 


\section{Functional and structural mitochondria studies}

Total mitochondrial mass, mitochondrial membrane potential $(\Delta \Psi m)$ and reactive oxygen species (ROS) were determined by FACS using MitotrackerGreen FM, tetramethylrhodamine, methyl ester (TMRM) and MitoSOX probes (Thermo Fisher), respectively. DNP (2,4-dinitrophenol) was used as $\Delta \Psi m$ negative control. Dead cells were excluded by diamino-2-phenylindol (DAPI) staining. Mitochondrial DNA (mtDNA) was extracted from $\mathrm{hCD}^{+}$cells with the DNeasy Blood and Tissue kit (Qiagen) and quantified by RT-qPCR using primers for MTTL1 tRNA (Leu)(UUR) [25]; the $\alpha 2$-microglobulin gene was used for normalization.

Immunofluorescence analyses were performed in paraformaldehyde-fixed $\mathrm{CD}^{+} \mathrm{T}$ cells, permeabilized with Triton X-100 (0.1\%). After blocking, cells were stained sequentially with anti-human aconitase-2 (6F12BD9, Abcam) and goat anti-mouse Alexa 488 (Molecular Probes). Samples were mounted in Prolong Gold Antifade Reagent with DAPI (Cell Signaling) and images captured in a Leica Microsystems microscope (LAS X v2.01; 60x objective). Mitochondrial morphology was determined with ImageJ [26].

For transmission electron microscopy, fixed cells were treated sequentially with $1 \%$ osmium tetroxide (TAAB Laboratories) and 2\% aqueous uranyl acetate, dehydrated with acetone, embedded in EPON 812 resin, and polymerized. Ultrathin sections (70 nm-thick; Ultracut EM UC6, Leica Microsystems) in 200 mesh nickel EM grids (Gilder) were stained with $3 \%$ aqueous uranyl acetate and lead citrate, and analyzed on a JEOL JEM 1011 electron microscope. The number of mitochondria per cell and cristae length were quantified by two independent observers blind to the experiment.

\section{CHCHD3 silencing experiments}

Lentiviruses encoding $\mathrm{CHCHD} 3$ or control short hairpin RNA (shRNA; Genecopoeia) were produced in HEK$293 \mathrm{~T}$ cells. Prior to transduction, $\mathrm{hCD}^{+}$cells were stimulated with anti-CD3- and -CD28 antibody-coated beads, then transduced with viral supernatants at 10-20 m.o.i in the presence of polybrene. CHCHD3 silencing was determined by qPCR and by immunoblot.

\section{Statistical analysis}

Normal or parametric distribution of the data was analyzed. For comparison between two conditions, data were analyzed with the Mann-Whitney $U$ test. For multiple non-parametric comparisons, Kruskal-Wallis followed by Dunn's post-test was used. For multiple parametric comparisons, data were analyzed by one- or two-way ANOVA with the Bonferroni post-hoc test. For the same samples with different treatments, paired Student's $t$-test was performed for two comparisons or paired repeated-measures one-way ANOVA for more than two conditions. Differences were considered significant when $p<0.05$. All statistical analyses were performed using Prism 7.0 software (GraphPad).

\section{Results}

RNA-seq distinguishes specific PD-1-induced gene sets in human $\mathrm{CD}^{+} \mathrm{T}$ cells

To determine how PD-1 signals change gene expression during activation of human (h) $\mathrm{CD}^{+} \mathrm{T}$ cells, we used an in vitro system that mimics the simultaneous engagement of PD-1 and the TCR/CD3 complex. Purified $\mathrm{hCD}^{+} \mathrm{T}$ cells were stimulated with magnetic beads conjugated with stimulating anti-CD3 and -CD28 antibodies ( $\mathrm{T}_{\mathrm{ACT}}$ cells), or with anti-CD3, anti-CD28, and PD-L1-Ig

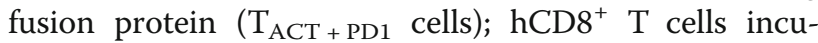
bated $6 \mathrm{~h}$ with polyclonal IgG-conjugated beads were used as control ( $\mathrm{T}_{\mathrm{CTRL}}$ cells). In these conditions, PD-1 consistently inhibited $\mathrm{hCD}^{+} \mathrm{T}$ cell activation and effector functions, determined by a reduction in CD25, CD69 and IFN $\gamma$ expression (Fig. 1a-d), as well as decreased proliferation (Fig. 1e). The PD-1-induced reduction was dose-dependent (Additional file 3: Figure S1).

Total RNA was isolated from $\mathrm{T}_{\mathrm{CTRL}}, \mathrm{T}_{\mathrm{ACT}}$ and $\mathrm{T}_{\mathrm{ACT}+}$ PD1 at 6, 24 and $48 \mathrm{~h}$ post-stimulation, and gene expression analyzed by RNAseq. MA plots representing log2fold changes (FC) against mean normalized counts were generated for all experimental conditions (Additional file 4: Figure S2; red dots indicate significant genes with a $10 \%$ false discovery rate (FDR)). Principal components analysis (PCA; Fig. 1f) and hierarchical clustering of the top 200 most-variable genes across samples (Fig. 1g) were used to determine similarity between expression profiles. These analyses clustered the three biological replicates of $\mathrm{T}_{\mathrm{ACT}}$ cells at each time analyzed; these analyses also differentiated $\mathrm{T}_{\mathrm{ACT}+\mathrm{PD} 1}$ samples after 24 and $48 \mathrm{~h}$ stimulation from the $\mathrm{T}_{\mathrm{CTRL}}$ and $\mathrm{T}_{\mathrm{ACT}+\mathrm{PD} 1}$ after $6 \mathrm{~h}$ stimulation, which were very close or intermixed. Venn diagrams showed a number of unique sets of differentially expressed genes in the $\mathrm{T}_{\mathrm{ACT}+\mathrm{PD} 1}$ cells compared to $\mathrm{T}_{\mathrm{CTRL}}$ and $\mathrm{T}_{\mathrm{ACT}}$ counterparts (Fig. 1h). These results suggest that PD-1 engagement not only prevented $\mathrm{hCD}^{+} \mathrm{T}$ cell activation, but also triggered a specific transcriptional program in $\mathrm{hCD}^{+} \mathrm{T}$ cells.

PD-1 engagement impairs expression of metabolic genes in human $\mathrm{CD}^{+} \mathrm{T}$ cells

We used LRT to identify genes expressed differentially over time. This type of analysis identifies genetic patterns impaired by PD-1 engagement more reliably than direct comparison between $\mathrm{T}_{\mathrm{CTRL}}, \mathrm{T}_{\mathrm{ACT}}$ and $\mathrm{T}_{\mathrm{ACT}+\mathrm{PD1}}$ RNAseq data at each time point. LRT analysis identified 1651 genes with divergent expression between $\mathrm{T}_{\mathrm{ACT}}$ and $\mathrm{T}_{\mathrm{ACT}+\mathrm{PD} 1}\left(\mathrm{p}_{\text {inter }}<\right.$ 

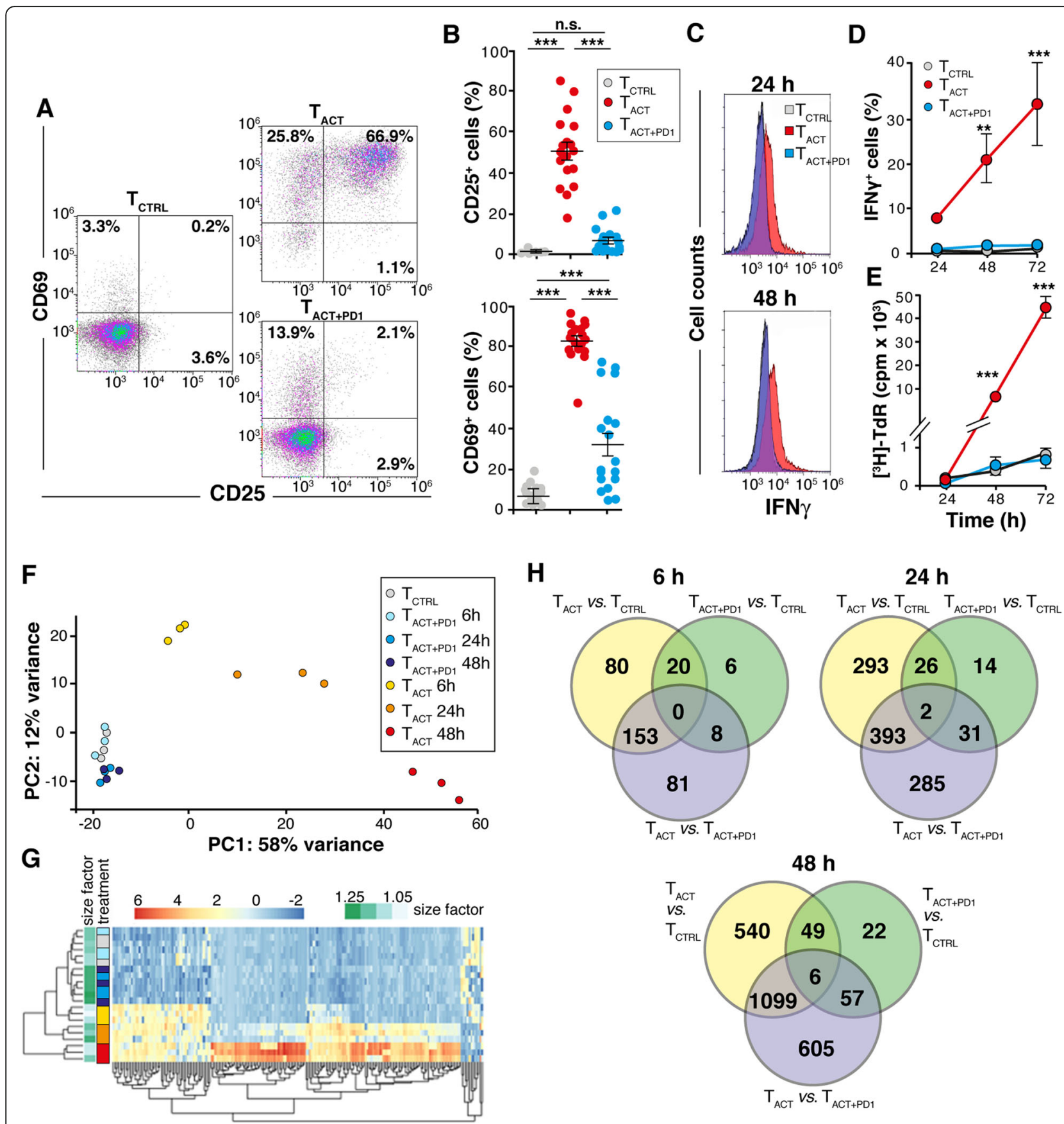

Fig. 1 Characterization of gene expression profiles in CD8 ${ }^{+} T$ cells after PD-1 ligation. a Representative dot plots showing CD25 and CD69 staining of primary human $C D 8{ }^{+} T$ cells after $48 \mathrm{~h}$ stimulation with $T_{C T R L} T_{A C T}$, and $T_{A C T}+P D 1$ beads. $\mathbf{b}$ Quantification of CD25- and CD69-expressing cells from dot plots as in $\mathbf{a}$. Each dot represents a donor $(n=18)$. $\mathbf{c}$ Representative histograms showing IFNy production by cells stimulated as in $\mathbf{a}$ for 24 and $48 \mathrm{~h}$. $\mathbf{d}$ Quantification of data from $\mathbf{c}(n=4)$. e Thymidine $\left(\left[{ }^{3} \mathrm{H}\right]-\mathrm{TdR}\right)$ incorporation by cells stimulated as in $\mathbf{a}(n=5)$. $\mathbf{f}$ PCA plot using the rlogtransformed values from the RNA-seq analysis. Each unique combination of cell stimulation and time is assigned a distinct color. $\mathbf{g}$ Hierarchical clustering dendrogram of the top 200 most-variable genes across samples. The heat map color code (left) uses the combination of cell stimulation/ time as in $\mathbf{f}$. $\mathbf{h}$ Venn diagrams showing the number of differentially expressed genes between indicated conditions at different times. For $\mathbf{d}$ and $\mathbf{e}$, data show mean \pm SEM. ${ }^{* *} p<0.01$; *** $p<0.001$, one-way $(\mathbf{b})$ or two-way ANOVA (d, e) with Bonferroni post-test

0.05), but only 578 passed FDR correction (Adj-pinter < $0.05)$; Additional file 5: Table S2 shows the top 20 genes in this analysis. KEGG pathway analysis using these 578 genes indicated that, in addition to pathways related to cell cycle and immune function, there was significant enrichment in metabolic genes, with 43 genes in this category (Fig. 2a; 


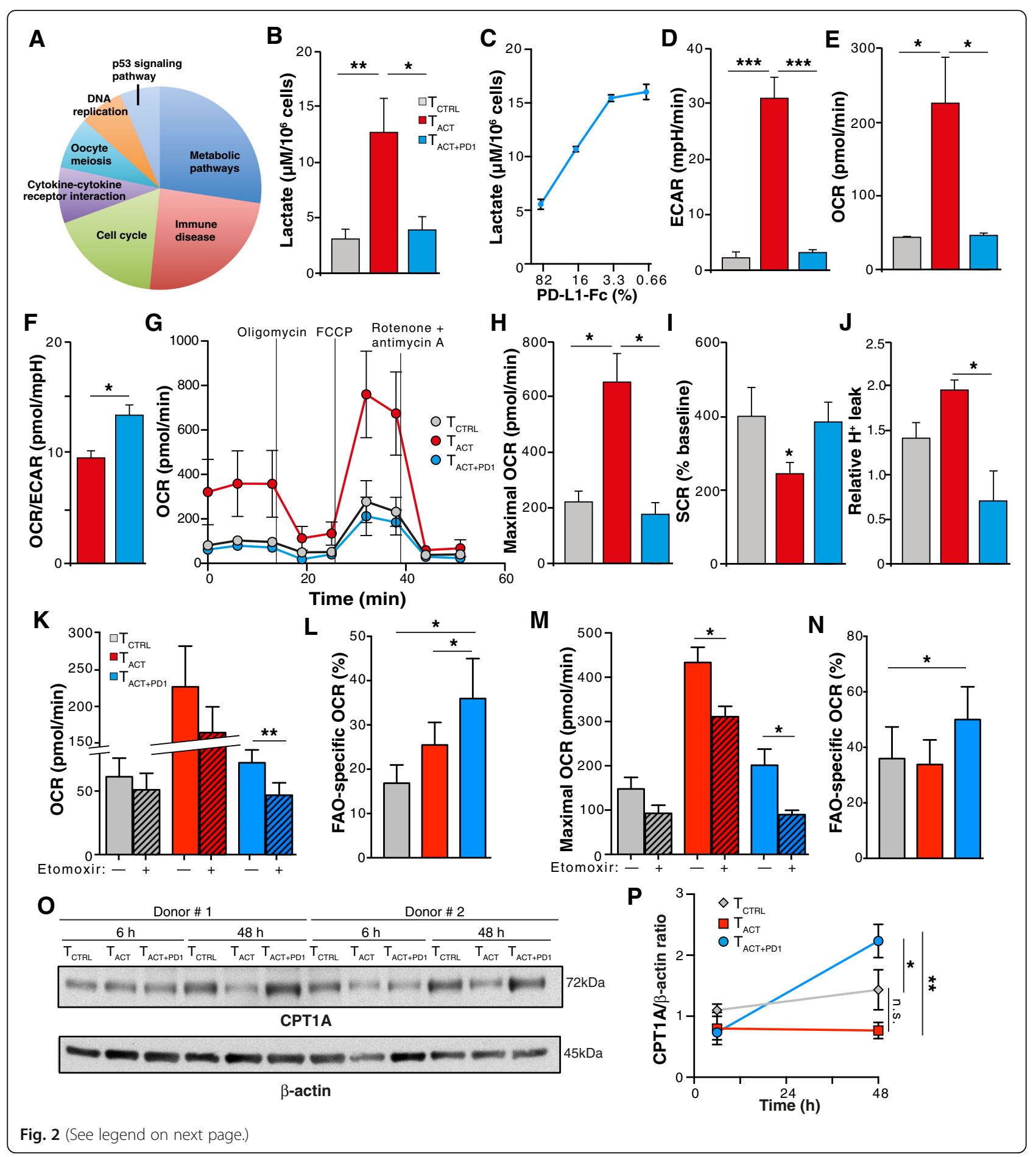


(See figure on previous page.)

Fig. 2 PD-1 ligation impairs mainly CD8 ${ }^{+} T$ cell metabolism. a KEGG signaling pathways with the highest scores significantly enriched in the 578 transcripts selected by LRT. $\mathbf{b}$ Lactate production in $\mathrm{hCD} 8^{+} \mathrm{T}$ cells stimulated $48 \mathrm{~h}$ with $\mathrm{T}_{\mathrm{CTRL}}, \mathrm{T}_{\mathrm{ACT}}$ and $\mathrm{T}_{\mathrm{ACT}+\mathrm{PD} 1}$ beads. $\mathbf{c}$ Lactate production in hCD8+ T cells stimulated $48 \mathrm{~h}$ with $\mathrm{T}_{\mathrm{ACT}+\mathrm{PD} 1}$ beads containing the indicated amounts of PD-L1-FC. $\mathbf{d}-\mathbf{f} \mathrm{hCD}{ }^{+} \mathrm{T}$ cells were stimulated with beads as in $\mathbf{b}$ and analyzed with SeaHorse. Basal extracellular acidification rate (ECAR; D), basal $\mathrm{O}_{2}$ consumption rate (OCR; e), and basal OCR/ECAR ratio (f). $\mathbf{g}$ OCR obtained during mitochondrial stress test in cells stimulated as in $\mathbf{b}$, performed by injection of oligomycin, the mitochondrial uncoupler FCCP, and the electron transport chain inhibitors antimycin A/rotenone. $\mathbf{h}$-j Maximal OCR obtained after FCCP injection (h), spare respiratory capacity (SRC; i) calculated as the difference between maximal and basal OCR, and relative proton leak (j) determined as OCR after oligomycin and subsequent injection of rotenone plus antimycin A. k-n hCD8 ${ }^{+} T$ cells were stimulated with beads as in $\mathbf{b}$, treated with etomoxir or vehicle and analyzed with SeaHorse, using palmitate as substrate. Basal OCR with vehicle (solid) or with etomoxir (hatched) (k), FAO-specific OCR from data in $\mathbf{k}(\mathbf{I})$, maximal OCR after FCCP injection in vehicle or etomoxir-treated cells ( $\mathbf{m})$, FAO-specific maximal OCR calculated from $\mathbf{m}$ (n). o Representative immunoblots for CPT1A and $\beta$-actin (loading control) in CD8 ${ }^{+} \mathrm{T}$ cells stimulated as indicated. $\mathbf{p}$ Densitometric analysis of immunoblots as in $\mathbf{o}$. The CPT1A/ $\beta$-actin ratio is shown, with the value for TCTRL cells as reference $(n=3$ donors). Data are mean \pm SEM from six $(\mathbf{b}, \mathbf{d}-\mathbf{j})$, four $(\mathbf{k}-\mathbf{n})$ or three $(\mathbf{p})$ donors; for $\mathbf{c}$, data are mean \pm SD representative of one donor from two. ${ }^{* *} p<0.01,{ }^{*} p<0.05$, Kruskal-Wallis with Dunn's post-hoc test for multiple comparisons $(\mathbf{b}, \mathbf{d}-\mathbf{f}, \mathbf{h}-\mathbf{k}, \mathbf{m})$, two-tailed Student's $t$-test $(\mathbf{I}, \mathbf{n})$, or two-way ANOVA with Newman-Keuls post-hoc test for multiple comparisons (p)

Additional file 6: Table S3). The primary metabolic processes with the most differentially regulated genes were amino acid, nucleotide and carbohydrate (glycolysis and the pentose phosphate) metabolism, the citrate cycle and OXPHOS (Additional file 7: Figure S3).

$\mathrm{GO}$ enrichment analysis of the 43 metabolic genes showed generation of precursor metabolites and energy and oxidative phosphorylation among the most represented biological processes (Additional file 8: Figure S4); the most represented molecular functions were NADH dehydrogenase and oxidoreductase activities (Additional file 9: Figure S5). Mitochondria and the respiratory chain were also identified as significantly enriched cellular components (Additional file 10: Figure S6).

\section{PD-1 engagement suppresses glycolysis and oxidative phosphorylation in $\mathrm{CD}^{+} \mathrm{T}$ cells}

To validate the transcriptional changes with metabolic alterations, we focused on glycolysis and OXPHOS, key metabolic pathways for $\mathrm{T}$ cell differentiation and function [13, 27]. We found that lactate production, a glycolysis indicator, was reduced in $\mathrm{T}_{\mathrm{ACT}+\mathrm{PD} 1}$ compared with $\mathrm{T}_{\mathrm{ACT}}$ cells, in a dose-dependent manner (Fig. 2b, c). $\mathrm{T}_{\mathrm{ACT}+\mathrm{PD} 1}$ cells similarly showed a significant ECAR reduction (Fig. 2d), which suggested that PD-1 ligation effectively inhibited the glycolytic pathway in $\mathrm{CD}^{+} \mathrm{T}$ cells. When we used high glucose levels as an energy source, basal OCR, an OXPHOS indicator, was significantly higher in $\mathrm{T}_{\mathrm{ACT}}$ than in $\mathrm{T}_{\mathrm{CTRL}}$ and $\mathrm{T}_{\mathrm{ACT}+\mathrm{PD} 1}$ cells (Fig. 2e); the OCR/ECAR ratio was nonetheless higher in $\mathrm{T}_{\mathrm{ACT}+\mathrm{PD} 1}$ than in $\mathrm{T}_{\mathrm{ACT}}$ cells (Fig. 2f), which suggested that $\mathrm{T}_{\mathrm{ACT}+\mathrm{PD} 1}$ cells preferentially use OXPHOS rather than glycolysis to generate ATP.

To analyze additional parameters of mitochondrial metabolism, we measured OCR in real time in basal conditions and after addition of several mitochondrial inhibitors (Fig. 2g). Addition of FCCP, which uncouples ATP synthesis from the electron transport chain, showed that maximal respiration capacity was higher in $\mathrm{T}_{\mathrm{ACT}}$ than in $\mathrm{T}_{\mathrm{CTRL}}$ and $\mathrm{T}_{\mathrm{ACT}+\mathrm{PD1}}$ cells (Fig. 2h). $\mathrm{T}_{\mathrm{CTRL}}$ and $\mathrm{T}_{\mathrm{ACT}+\mathrm{PD1}}$ cells nonetheless had a substantial mitochondrial SRC, as indicated by the difference between maximal and basal OCR (Fig. 2i). The elevated SRC, a parameter associated with longterm survival [14], and the higher OCR/ECAR ratio suggest more efficient OXPHOS in $\mathrm{T}_{\mathrm{ACT}+\mathrm{PD} 1}$ than in $\mathrm{T}_{\mathrm{ACT}}$ cells. Confirming this idea, proton leak (determined as OCR after oligomycin relative to OCR after rotenone and antimycin A) was significantly lower in $\mathrm{T}_{\mathrm{ACT}+\mathrm{PD} 1}$ than in $\mathrm{T}_{\mathrm{ACT}}$ cells (Fig. 2j); there was also a tendency to lower proton leak in $\mathrm{T}_{\mathrm{ACT}}+$ PD1 than in $\mathrm{T}_{\mathrm{CTRL}}$ cells (Fig. 2j).

To further study metabolic differences in the mitochondria of PD-1-stimulated cells, we measured OCR using palmitate as a substrate, alone or in the presence of etomoxir, which inhibits carnitine palmitoyltransferase 1A (CPT1A), a central enzyme for longchain fatty acid oxidation in mitochondria. Etomoxir led to greater inhibition of basal and maximal (after oligomycin and FCCP treatment) OCR in $\mathrm{T}_{\mathrm{ACT}+\mathrm{PD1}}$ than in $\mathrm{T}_{\mathrm{CTRL}}$ and $\mathrm{T}_{\mathrm{ACT}}$ cells (Fig. 2k-n), which indicated greater OXPHOS dependence on FAO in $\mathrm{T}_{\mathrm{ACT}+\mathrm{PD} 1}$ cells than in the other conditions. We also found time-dependent induction of CPT1A in $\mathrm{T}_{\mathrm{ACT}}+$ PD1 compared to $\mathrm{T}_{\mathrm{CTRL}}$ and $\mathrm{T}_{\mathrm{ACT}}$ cells (Fig. 2o, p), which might explain the mechanism underlying the higher FAO capacity of PD-1-stimulated cells. These results indicate that $\mathrm{PD}-1$ signals reprogram $\mathrm{CD}^{+} \mathrm{T}$ cell metabolism for efficient use of FAO-dependent mitochondrial OXPHOS, which resembles some aspects of long-lived memory $\mathrm{T}$ cells [14]. Moreover, the distinct FAO-dependent OXPHOS between $\mathrm{T}_{\mathrm{CTRL}}$ and $\mathrm{T}_{\mathrm{ACT}+\mathrm{PD1}}$ cells (Fig. 2l, n) suggests that PD-1induced metabolic changes are not simply blockade of $\mathrm{T}$ cell activation, but involve unique, time-dependent programs induced by PD-1 engagement. 
PD-1 ligation reduces mitochondrial polarization and ROS production

We analyzed mitochondria bioenergetics in live cells by combining the $\Delta \Psi \mathrm{m}$-sensitive TMRM and the $\Delta \Psi \mathrm{m}$ independent MitotrackerGreen probes; the depolarizing agent DNP was used as a TMRM staining control (Fig. 3a). Compared with $\mathrm{T}_{\text {CTRL }}$ cells, $\mathrm{CD}^{+} \mathrm{T}$ cell activation caused a significant increase in both the number of cells with polarized mitochondria (Fig. $3 \mathrm{~b}$ ) and the TMRM fluorescence bound to these mitochondria (Fig. 3c-d). PD-1 ligation abrogated the $\Delta \Psi \mathrm{m}$ increase caused by activation stimuli (Fig. 3c-d). Reactive oxygen species (ROS) production nonetheless did not differ statistically between $\mathrm{T}_{\mathrm{ACT}+\mathrm{PD} 1}$ and $\mathrm{T}_{\mathrm{ACT}}$ cells (Fig. 3e). It appears that although PD-1 affects mitochondrial function, these organelles retain some respiratory capacity compared to that of resting $\mathrm{T}_{\mathrm{CTRL}}$ cells.

We tested whether the PD-1 effects on $\Delta \Psi \mathrm{m}$ were reversible. $\mathrm{CD}^{+} \mathrm{T}$ cells were incubated with $\mathrm{T}_{\mathrm{ACT}+\mathrm{PD} 1}$ beads and, after PD-L1 washout, stimulated with $\mathrm{T}_{\mathrm{ACT}}$ or $\mathrm{T}_{\text {CTRL }}$ beads (Fig. 3f). Re-stimulation of $\mathrm{T}_{\mathrm{ACT}+\mathrm{PD1}}$ with $\mathrm{T}_{\text {CTRL }}$ beads indicated that pre-incubation of cells with PD-L1 reduced both the percentage of cells with polarized mitochondria as well as TMRM fluorescence intensity compared to $\mathrm{T}_{\mathrm{ACT}}$ cells. But more important, after re-stimulation with $\mathrm{T}_{\mathrm{ACT}}$ beads, the PD-L1preincubated cells did not recover either the percentage of $\mathrm{TMRM}^{+}$cells or fluorescence intensity to the levels observed in primary $\mathrm{T}_{\mathrm{ACT}}$ cells (Fig. $3 \mathrm{~g}$, h). These results suggest that PD-1 effects on these mitochondrial parameters were irreversible.

\section{PD-1 controls expression of genes involved in mitochondrial structure and function}

Of the 578 genes selected by LRT, 84 coded for transcripts enriched in mitochondrial-related GO categories (Additional file 11: Figure S7). These 84 genes were not only related to metabolic pathways, but also included

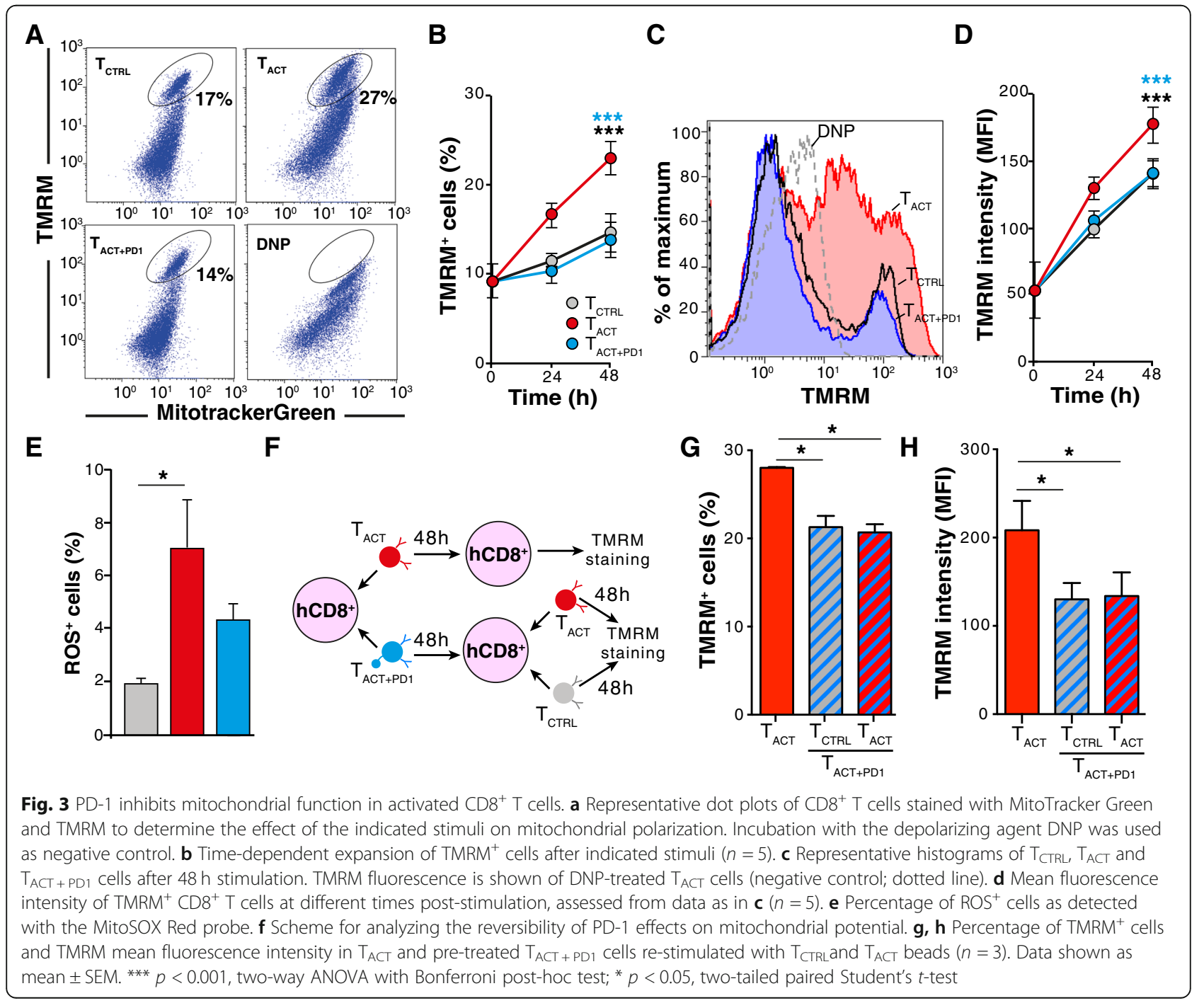


those involved in mitochondrial DNA replication and repair (FEN1, TOP2A, XRCC3), translation (POP7, MRPL39, MRPS12), protein import machinery (TIMM22, TIMM23, TOMM34), fusion/fission (MIEF1, $M T C H 1)$, cristae structure and organization ( $\mathrm{CHCHD} 3$, CHCHD10, HSPA9), and assembly of protein complexes of the respiratory chain (ATP5G1, COX8A, NDUFB3, SELRC1, UQCRC2) (Additional file 12: Table S4).

We used STEM software [23] to analyze and cluster our gene expression dataset more stringently. STEM clustering of $\log \mathrm{FC}$ values generated eight model expression profiles significantly enriched $(\mathrm{FDR}<0.05)$ for transcripts expressed longitudinally in $\mathrm{T}_{\mathrm{ACT}} \mathrm{vs} \mathrm{T}_{\mathrm{ACT}+\mathrm{PD} 1}$ cells (Fig. 4a). Profile A, which clustered transcripts whose expression increased over time in $\mathrm{T}_{\mathrm{ACT}}$ compared to $\mathrm{T}_{\mathrm{ACT}}+\mathrm{PD1}$ cells, was specifically enriched for genes in Mitochondrial Protein Complex (including ATP5G1, CHCHD3, COX8A, DNA2, NDUFAB1, NDUFB3, NDUFB7, PPIF, TIMM22, TIMM23, TOMM40, TOMM4OL and UQCRC2), as well as in 27 transcripts of other mitochondrial-related profiles (Fig. 4b). This finding suggests that genes involved in mitochondrial structure and function tend to be upregulated in $\mathrm{T}_{\mathrm{ACT}}$ rather than $\mathrm{T}_{\mathrm{ACT}}+$ PD1 cells.

STEM also identified profile $B$, which included transcripts whose expression decreased with time in $\mathrm{T}_{\mathrm{ACT}}$ relative to $\mathrm{T}_{\mathrm{ACT}+\mathrm{PD} 1}$ cells (Fig. 4a). Profile $\mathrm{B}$ was enriched in GO categories related to transmembrane receptors and ion binding activities (Additional file 13: Table S5), but none of these genes was significant after multiple comparison correction.

Using $\mathrm{qPCR}$ in an independent set of samples, we validated the differential expression of a series of mitochondrial genes (Fig. 4c), including HSPA9 (chaperone), CHCHD3, CHCHD 10 and PHB (cristae morphogenesis), and MIEF1, MTFP1 and MTFR2 (mitochondrial fission); repression of these genes was PD-1 dose-dependent (Additional file 14: Figure S8). Consistent with their transcriptomic upregulation, $\mathrm{CHCHD} 3, \mathrm{CHCHD} 10$ and MTFR2 protein levels were increased in $\mathrm{T}_{\mathrm{ACT}}$ compared to $\mathrm{T}_{\mathrm{ACT}}+\mathrm{PD} 1$ cells, as detected by immunoblot (Fig. 4d, e). $\mathrm{T}_{\mathrm{ACT}}$ cells also showed a general tendency to upregulate other mitochondrial proteins such as the chaperone HSP60 and the fatty acid betaoxidation protein HADHA, although variability among donors precluded significance. Expression of the mitochondrial respiratory chain proteins NDUFA9 (complex I), SDH-B (complex II), CORE II (complex III) and $\beta$-F1ATPase (complex V) showed no statistical difference between $\mathrm{T}_{\mathrm{ACT}}, \mathrm{T}_{\mathrm{ACT}+\mathrm{PD1}}$ and $\mathrm{T}_{\mathrm{CTRL}}$ cells, although NDUFA9 tended to be downregulated in $\mathrm{T}_{\mathrm{ACT}}$ cells. We could not analyze expression differences in complex IV (cox-IV and cox8A) due to deficient antibody function or protein insolubility.

\section{PD-1 reduces mitochondrial number but does not affect} dynamics

We analyzed whether different treatments influenced cell mitochondrial mass. HSP60 is a marker of mitochondrial biogenesis [26]. Consistent with the tendency to HSP60 downmodulation in $\mathrm{T}_{\mathrm{ACT}+\mathrm{PD} 1}$ cells, mitochondrial number was significantly reduced in $\mathrm{T}_{\mathrm{ACT}}+$ PD1 compared to $\mathrm{T}_{\mathrm{ACT}}$ cells, as determined by direct counting (Fig. 5a; Additional file 15: Figure S9A-C), relative mtDNA quantity (Fig. $5 \mathrm{~b}$ ), or MitotrackerGreen staining (Fig. 5c, d). In contrast, mitochondrial mass was statistically unchanged between $\mathrm{T}_{\mathrm{ACT}}$ and $\mathrm{T}_{\text {CTRL }}$ cells (Fig. 5a-d). As for $\Delta \Psi \mathrm{m}$, cell pre-incubation with PD-L1 reduced mitochondrial mass, which was not reversed after their re-stimulation with $\mathrm{T}_{\mathrm{ACT}}$ beads (Fig. 5e).

Mitochondrial morphology and number in $\mathrm{T}$ cells is influenced dynamically by the processes of fusion and fission [26]. PD-1 stimulation downregulated mRNA and protein levels of MTFR2 (Fig. 4c-e), a mitochondrial fission promoter [28]. We thus measured mitochondrial interconnectivity and shape from confocal micrographs of aconitase 2-stained $\mathrm{T}_{\mathrm{CTRL}}, \mathrm{T}_{\mathrm{ACT}}$ and $\mathrm{T}_{\mathrm{ACT}+\mathrm{PD1}}$ cells (Fig. 5f). We found no differences in mitochondrial circularity, a criterion related to fission/fusion events [29], in the cell types analyzed (Fig. $5 \mathrm{~g}$ ). Moreover, we detected no changes associated to cell treatment in mRNA or protein levels of OPA-1 or DRP-1 (Fig. 5h-j), two master regulators of mitochondrial fusion and fission [26]. Although PD-1 downmodulates MTFR2, it thus seems insufficient to substantially affect mitochondrial dynamics. In a very small number of $\mathrm{T}_{\mathrm{ACT}}+\mathrm{PD} 1$ cells, we found discrete mitochondria engulfed by doublemembrane structures that resembled autophagosomes (Additional file 15: Figure S9D). Nevertheless, we detected no differential expression of mitophagy-associated genes in $\mathrm{T}_{\mathrm{ACT}}+\mathrm{PD1}$ cells (not shown).

\section{PD-1 decreases the number and length of mitochondrial cristae}

Although several reports linked PD-1 to functional mitochondrial impairment [15, 17-19], the structural changes in mitochondria from $\mathrm{PD}-1$-stimulated $\mathrm{CD} 8^{+} \mathrm{T}$ cells have not been described in detail. PD-1 downregulated two genes, CHCHD3 (also termed Mic19) and CHCHD10 (Mic14; Fig. 4d, e), which form part of the mitochondrial contact site and MICOS [30]. In mammalian cells, the MICOS is a multimeric complex composed of nine known subunits and putative interactors, which links the inner boundary to the outer mitochondrial membranes and stabilizes cristae junctions [30].

Ultrastructural analyses showed clear differences in the organization of the inner mitochondrial membrane and cristae (Fig. 6a). Mitochondria from $\mathrm{T}_{\mathrm{ACT}}$ cells had a large number of tight cristae, with a parallel-oriented 


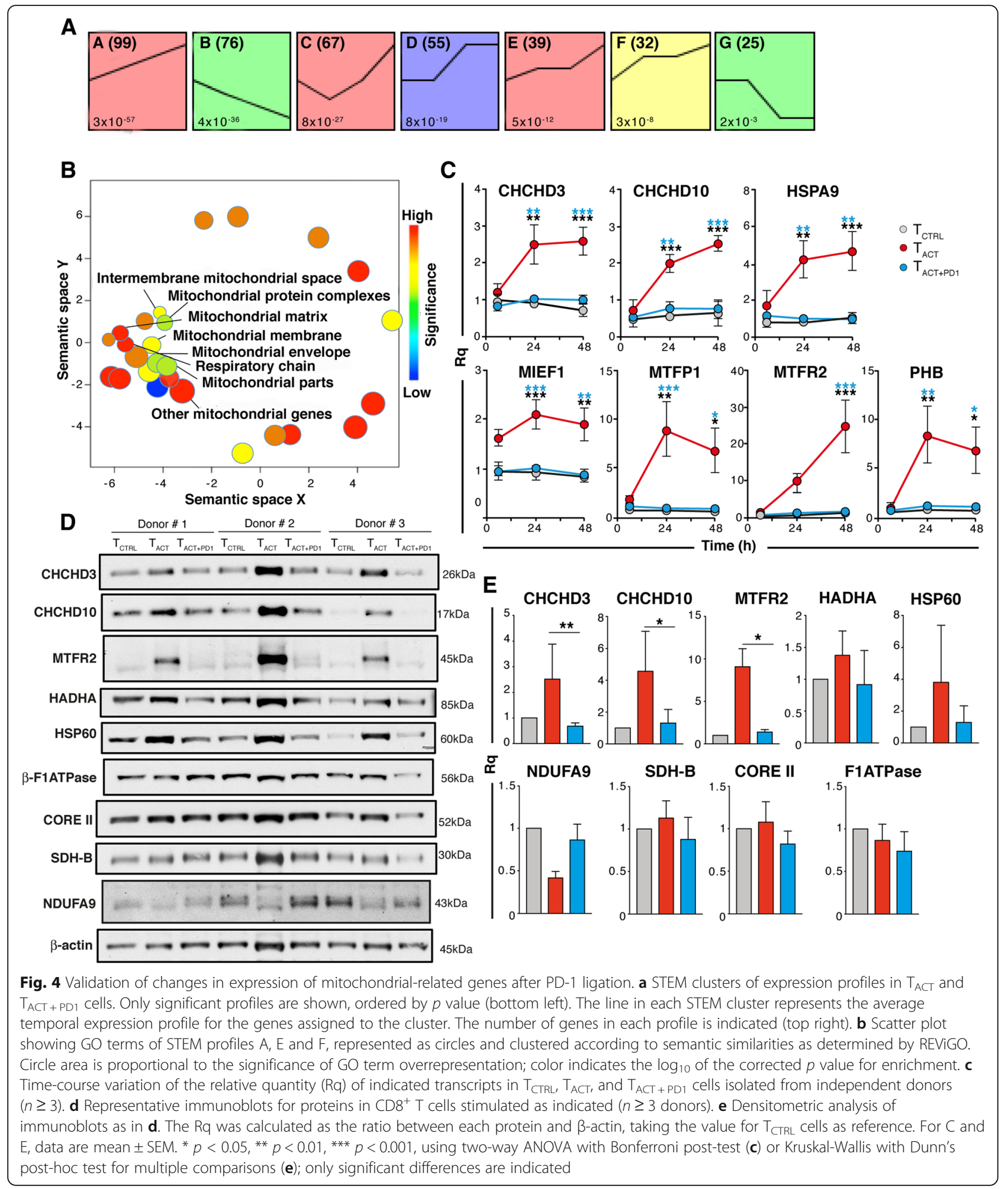

lamellar profile (Fig. 6a). This contrasted with the loose vesicular profile of cristae in $\mathrm{T}_{\mathrm{CTRL}}$ cells. $\mathrm{T}_{\mathrm{ACT}+\mathrm{PD1}}$ cell mitochondria also had some swollen cristae, although they did not show the clear vesicular profile observed in

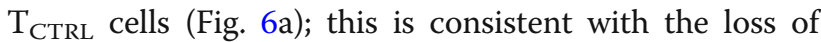

respiratory capacity and transcriptomic downregulation of structural proteins. Moreover, $\mathrm{T}_{\mathrm{ACT}+\mathrm{PD} 1}$ cell mitochondria often lacked visible cristae (Fig. 6a). The percentage of mitochondria without cristae was significantly larger in $\mathrm{T}_{\mathrm{ACT}+\mathrm{PD} 1}$ than in $\mathrm{T}_{\mathrm{ACT}}$ cells (Fig. 6b). 


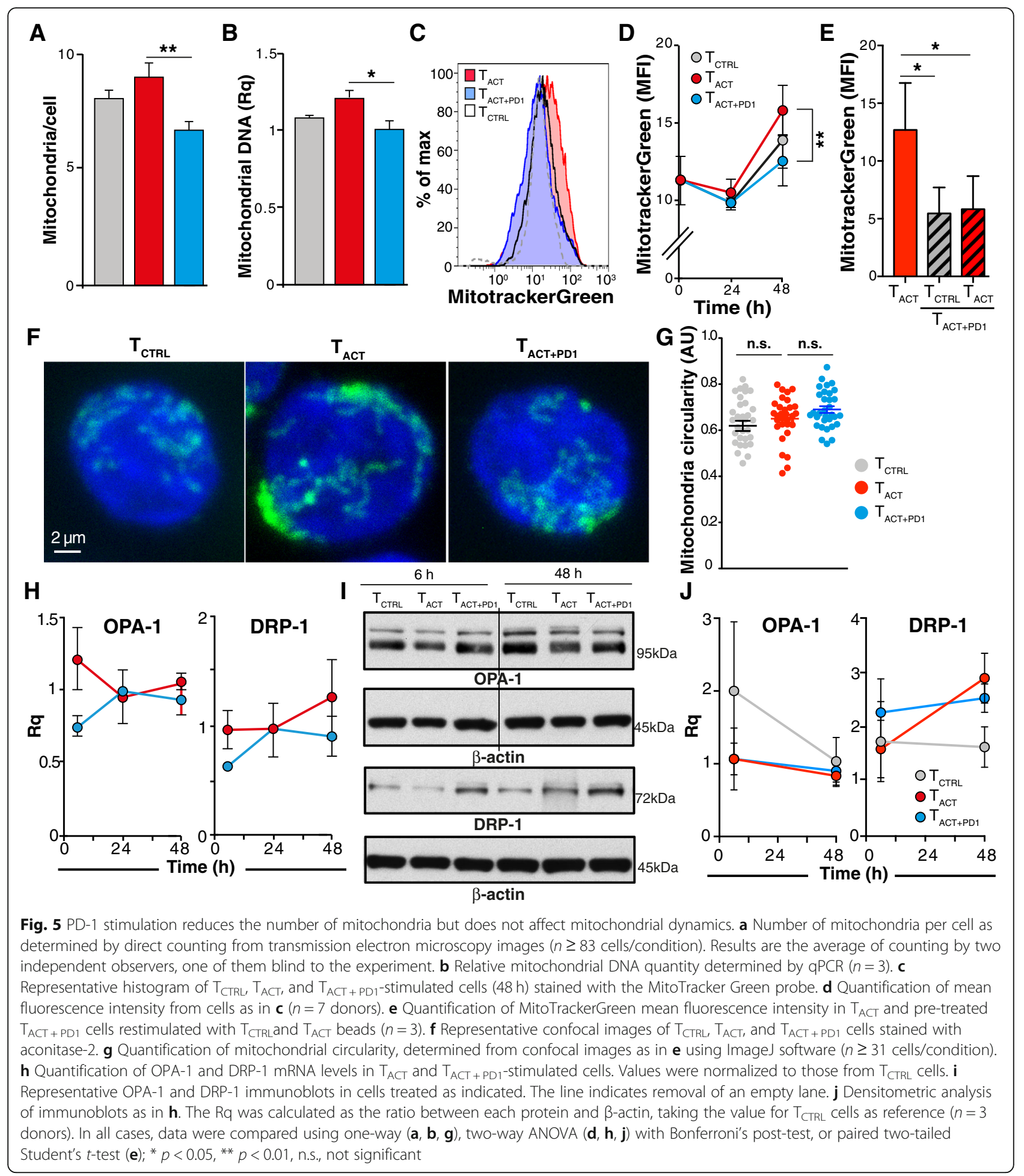

Although $\mathrm{T}_{\mathrm{CTRL}}$ cells also had a larger number of mitochondria without cristae than $\mathrm{T}_{\mathrm{ACT}}$ cells (Fig. 6b), the differences were not significant $(p=0.14$; Fisher's exact test). The number of cristae per mitochondrion and the length of these cristae was significantly reduced in $\mathrm{T}_{\mathrm{ACT}}+$ PD1 compared to $\mathrm{T}_{\mathrm{ACT}}$ cells (Fig. 6c, d). The results suggest that PD-1-induced downmodulation of these MICOSassociated proteins affect cristae organization.

We tested whether PD-1-induced CHCHD3 downregulation is responsible for the dysfunctional state of mitochondria. Purified, activated $\mathrm{CD}^{+} \mathrm{T}$ cells were transduced with lentiviruses encoding control or 


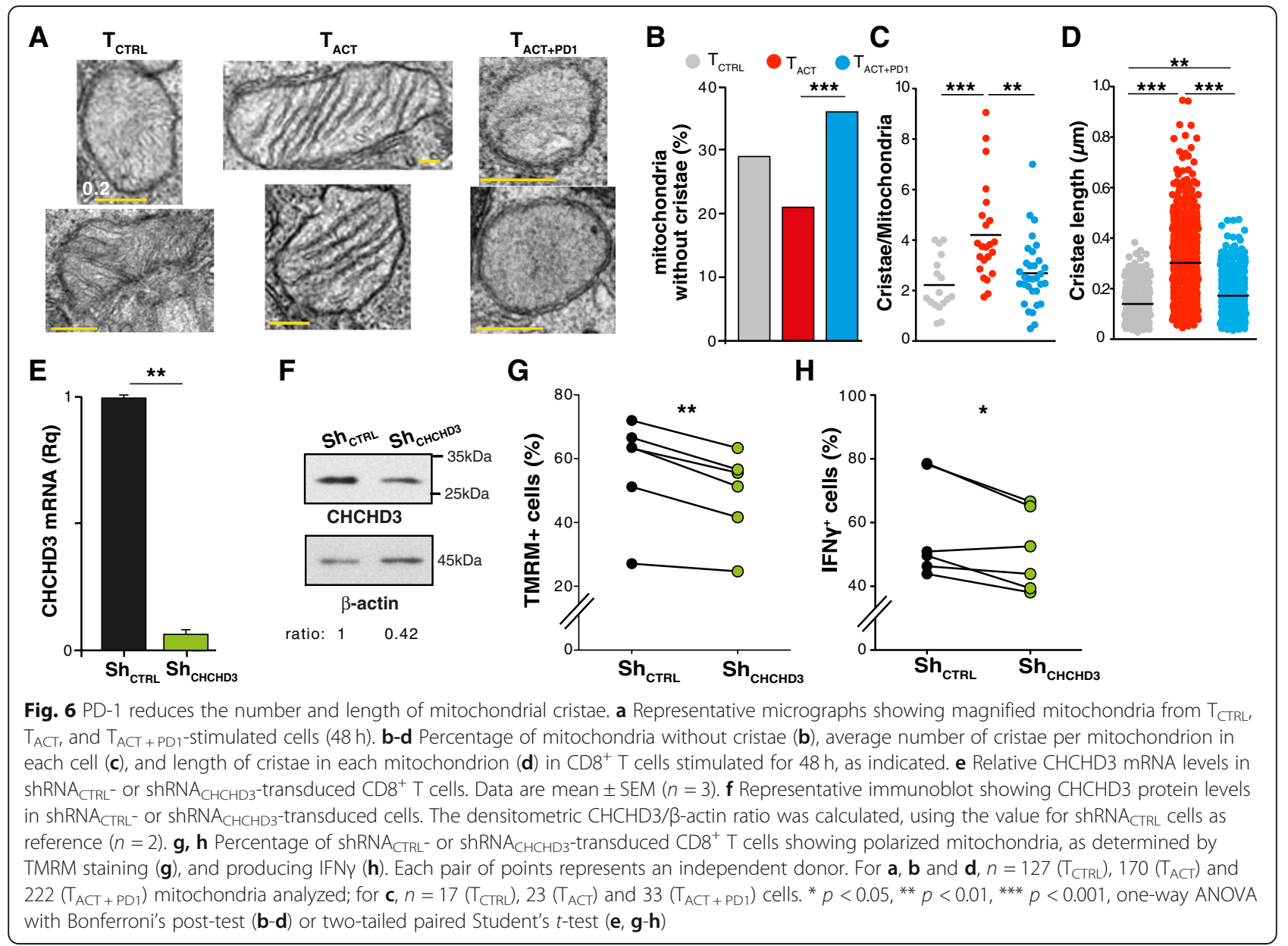

CHCHD3 short hairpin (sh)RNA; transduction efficiency was $11-53 \%$. CHCHD3-shRNA effectively downregulated $\mathrm{CHCHD} 3 \mathrm{mRNA}$ and protein levels at $48 \mathrm{~h}$ posttransduction (Fig. 6e, f). Transduced cells were then reactivated, and mitochondrial polarization and IFN $\gamma$ production analyzed in shRNA-expressing cells (gated by GFP co-expression). CHCHD3 silencing caused a significant reduction in the polarization of mitochondria (Fig. $6 \mathrm{~g}$ ) and in IFN $\gamma$ production (Fig. 6h), indicating that downregulation of a single MICOS-associated protein is sufficient to produce mitochondrial dysfunction and to impair T cell activation.

\section{Alterations in mitochondrial cristae are associated with increased supercomplex assembly}

Individual respiratory chain complexes can be organized in quaternary supramolecular structures termed supercomplexes (RCS) [31, 32]. These RCS reside in the inner mitochondrial membrane, and establish an efficient proton gradient for complex V to synthesize ATP [33]. Although the precise RCS arrangement is largely unknown, high-resolution structural models of the mammalian respirasome have been described [34-37].
Since RCS are highly enriched in the cristae membrane $[31,32]$ and their formation/stability is linked to cristae shape [38], we tested whether the morphological changes in the $\mathrm{T}_{\mathrm{ACT}}+\mathrm{PD} 1$ cell cristae affected RCS formation. To our surprise, we found greater enrichment of RCS containing complexes I and III in mitochondrial membranes of $\mathrm{T}_{\mathrm{ACT}+\mathrm{PD} 1}$ and $\mathrm{T}_{\mathrm{CTRL}}$ than of $\mathrm{T}_{\mathrm{ACT}}$ cells (Fig. 7a-d); in contrast, complex III dimers were represented equally in all cell types (Fig. 7a-d).

We searched our RNA-seq data for differentially regulated genes that could explain the increased RCS formation or stability in $\mathrm{T}_{\mathrm{ACT}+\mathrm{PD1}}$ and $\mathrm{T}_{\mathrm{CTRL}}$ cells, focusing on the co-chaperone MCJ (methylation-controlled J protein; also termed DnaJC15), which is described as a negative regulator of RCS formation/stability in $\mathrm{CD}^{+} \mathrm{T}$ cells [39]. We found time-dependent MCJ/DnaJC15 mRNA upregulation in $\mathrm{T}_{\mathrm{ACT}}$ compared to $\mathrm{T}_{\mathrm{ACT}+\mathrm{PD} 1}$ and $\mathrm{T}_{\mathrm{CTRL}}$ cells (Fig. 7e).

\section{Discussion}

Reactivation of tumor-specific T cells through PD-1/PDL1 axis blockade has emerged as a prominent immunotherapeutic option for many cancers. Little is known of 


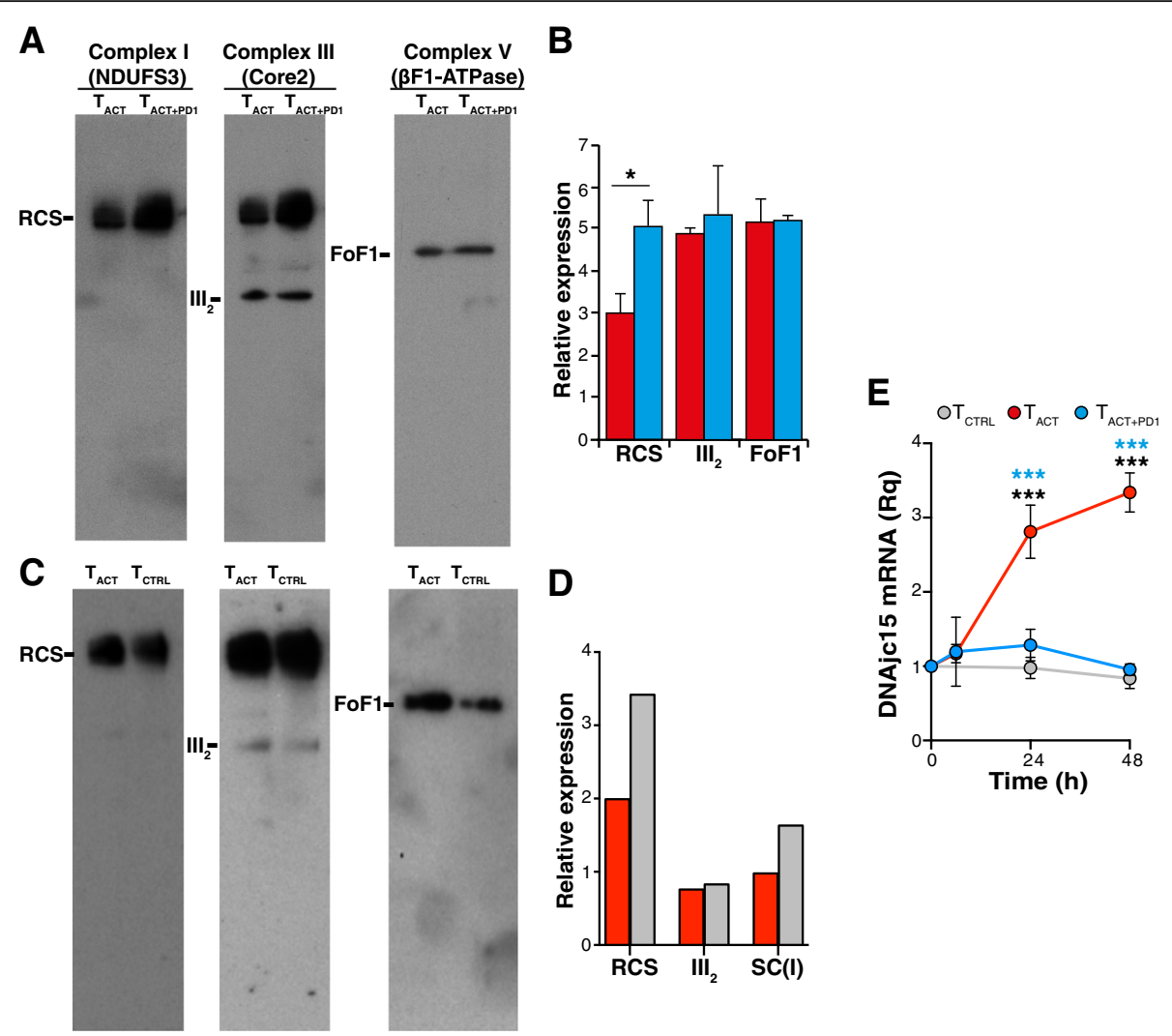

Fig. 7 PD-1 increases the formation of supercomplexes. a Representative blue native PAGE showing RCS formation in $T_{A C T}$, and $T_{A C T}+P D 1^{-}$ stimulated cells $(48 \mathrm{~h}$ ). Blots were hybridized sequentially with anti-NDUFS3 (complex I), -Core2 (complex III) and - $\beta$ F1-ATPase (complex V) antibodies. $\mathbf{b}$ Densitometric quantification of the blots shown in $A\left(n=4 ;{ }^{*}, p<0.05\right.$, paired two-tailed Student's $t$-test). c Blue native PAGE showing RCS formation in $T_{A C T}$ and $T_{\text {CTRL }}$ cells (48 h); hybridizations were as in a. $\mathbf{d}$ Densitometric quantification of the blots shown in $\mathbf{c}$. Data shown are from a pool of three donors. e Relative MCJ/DnaJC15 mRNA levels in $T_{C T R L} T_{A C T}$ and $T_{A C T}+$ PD1 cells at different times post-stimulation with indicated beads. Values were normalized to unstimulated cells (time 0). Data are mean \pm SEM $\left(n=3\right.$ independent donors). ${ }^{* * *} p<0.001$, twoway ANOVA with Bonferroni's post-hoc test

the inhibitory signals transduced by PD-1 that hinder T cell anti-tumor activity. Several reports defined genomewide transcriptional programs and the underlying molecular circuitry in exhausted $\mathrm{CD} 8^{+} \mathrm{T}$ cells, based on lymphocytes isolated from animals infected with viruses that induce exhaustion [40,41], or from the tumor microenvironment $[15,19,42]$. Since the exhaustion program is not mediated exclusively by PD-1 signaling [43], the genetic programs identified cannot be ascribed entirely to PD-1 activity in these cells. Our system was designed to define specific genetic programs regulated after PD-1 engagement, constituting an ideal method to identify signaling pathways controlled by this inhibitory receptor. Principal component analysis and hierarchical clustering showed clear commonalities in the transcriptional programs of resting and PD-L1-stimulated cells at $6 \mathrm{~h}$. In contrast, expression profiles of $\mathrm{T}_{\mathrm{ACT}+\mathrm{PD} 1}$ cells stimulated for 24 and $48 \mathrm{~h}$ segregated from that of resting cells. Our data for human $\mathrm{CD}^{+} \mathrm{T}$ cells thus indicate that PD-1 elicits a unique, time-dependent transcriptomic program that differs from that in resting $\mathrm{T}$ cells. Further research is warranted to study the potential of these PD-1-induced/repressed genes in the inhibition of $\mathrm{T}$ cell effector function.

A set of 1651 genes showed significant divergence of expression between $\mathrm{T}_{\mathrm{ACT}}$ and $\mathrm{T}_{\mathrm{ACT}+\mathrm{PD1}}$ cells, although only 578 passed the FDR correction. Signaling pathway enrichment analyses indicated metabolism as the process with the largest number of genes with differing expression between these conditions. From the metabolic pathways inferred to be targeted, we showed that PD-1 significantly reduced $\mathrm{CD}^{+} \mathrm{T}$ cell capacity to switch on glycolysis and mitochondrial respiration (determined by reduced basal and maximal OCR) following activation using glucose as a substrate. We nonetheless found that the OCR/ECAR ratio was significantly higher in $\mathrm{T}_{\mathrm{ACT}}+$ PD1 than in $\mathrm{T}_{\mathrm{ACT}}$ cells, as reported for PD-1-stimulated $\mathrm{CD}^{+} \mathrm{T}$ cells $[16,44]$. Glycolysis inhibition in PD-1stimulated cells can be explained by the reported activation of the phosphatase PTEN and subsequent 
downmodulation of the AKT/mTOR pathway, downstream of PD-1 [20]. PD-1-mediated inhibition of basal and maximal respiration rates could be a result of reduced expression and/or decreased activity after covalent modification of respiratory chain proteins by phosphorylation [45-47].

Our results also suggest that metabolic changes induced by PD-1 are not simply the consequence of PD-1 inhibitory activity on $\mathrm{T}$ cell activation. Indeed, using palmitate as a substrate, we found that FAO-dependent OCR was higher in $\mathrm{T}_{\mathrm{ACT}+\mathrm{PD1}}$ than in resting $\left(\mathrm{T}_{\mathrm{CTRL}}\right.$ ) cells. This FAO elevation was associated to a timedependent increase in CPT1A expression specifically in $\mathrm{T}_{\mathrm{ACT}}+\mathrm{PD} 1$ cells. Moreover, relative proton leak was also lower in $\mathrm{T}_{\mathrm{ACT}+\mathrm{PD} 1}$ than in $\mathrm{T}_{\mathrm{ACT}}$ or $\mathrm{T}_{\mathrm{CTRL}}$ cells, a phenotype reported for memory $\mathrm{T}$ cells, which are characterized by efficient mitochondrial respiration [48]. These data suggest that PD- 1 shapes $\mathrm{CD}^{+} \mathrm{T}$ cell metabolism similar to long-lived cells, and provides a mechanistic explanation for the long-lived characteristics of tumor-infiltrating lymphocytes (TIL) in a metabolically insufficient tumor microenvironment.

Our study showed that mitochondrial number and function (impaired $\Delta \Psi \mathrm{m}$ ) were restrained in $\mathrm{T}_{\mathrm{ACT}}+\mathrm{PD1}$ cells. It is difficult to assess which of these two alterations is more important for explaining PD-1-induced metabolic dysfunction. It is noteworthy that the tumor microenvironment represses mitochondrial biogenesis [15], whereas 4-1BB costimulation increases mitochondria numbers in $\mathrm{CD}^{+} \mathrm{T}$ cells [49]; our data thus concur with the hypothesis that variation in mitochondria number might be a regulatory target for co-stimulatory and inhibitory receptors. RNA-seq data showed differential expression between $\mathrm{T}_{\mathrm{ACT}}+\mathrm{PD} 1$ and $\mathrm{T}_{\mathrm{ACT}}$ cells of 84 genes coding for mitochondrial proteins. Among these, we found mitochondria biogenesis markers such as HSP60, and some fusion/fission regulators such as MTFP1 and MTFR2, which were validated as downmodulated in PD-1-stimulated cells at both transcriptomic and protein levels. No alterations were detected between $\mathrm{T}_{\mathrm{ACT}+\mathrm{PD} 1}$ and $\mathrm{T}_{\mathrm{ACT}}$ cells in mitochondria circularity and interconnectivity, two criteria related to fusion/fission processes [29]. Expression of OPA-1 and DRP-1, two major regulators of mitochondria fusion/fission events, was also unaltered by PD-1 engagement. We found some images resembling mitophagy exclusively in $\mathrm{T}_{\mathrm{ACT}+\mathrm{PD} 1}$ cells, although mitophagy-inducing genes were not induced in these cells. It is possible that the moderate reduction of mitochondria number in $\mathrm{T}_{\mathrm{ACT}}+$ PD1 cells might be a sum of discrete events.

Neither the PD-1-induced $\Delta \Psi \mathrm{m}$ inhibition nor mitochondria number reduction can be rescued by PD-1 washout. These results coincide with previous reports indicating that repression of mitochondrial activity in the tumor microenvironment cannot be rescued by PD1 blockade [15]. There is, in fact, a heritable epigenetic mechanism that drives $\mathrm{T}$ cell exhaustion, which is not completely reversed by anti-PD-1 blockade [50]. A mechanistic explanation for our results might thus be that PD-1 engagement caused epigenetic reprograming of $\mathrm{CD}^{+} \mathrm{T}$ cells, which led to irreversible functional alteration of the mitochondria. Further research is needed to verify this hypothesis. The irreversibility of mitochondria function as well as the preferential use of FAO in $\mathrm{T}_{\mathrm{ACT}+\mathrm{PD} 1}$ cells thus suggest that PD-1 engagement induces a metabolic program different from that of resting $\mathrm{T}$ cells.

Ultrastructural analyses also revealed notable changes in inner mitochondrial membrane organization in $\mathrm{T}_{\mathrm{ACT}}+\mathrm{PD1}$ cells, with a severe reduction in cristae/mitochondrion length and number, or even in their complete loss. In lung cancer patients, mitochondria from TIL with high PD-1 levels show fewer and shorter cristae than those in TIL with low or no PD-1 expression [19]. The mitochondrial cristae phenotype observed here after PD-1 engagement appears to correspond to a true defect of cytotoxic lymphocytes exposed in vivo to PD-1 stimulation.

CHCHD3 is an important regulator in the organization and stability of the MICOS complex, as it links the inner and outer mitochondrial membranes through interaction with SAM50 [30]. Our analysis indicated consistent downregulation of two MICOS complex proteins, CHCHD3 and CHCHD10. Given the low transfection efficiency of primary $\mathrm{CD} 8^{+} \mathrm{T}$ lymphocytes, we were unsuccessful in simultaneously silencing CHCHD3 and CHCHD10. In yeast, the soluble $\mathrm{CHCHD} 3$ protein functions as the key component in directing the inner membrane distribution of each MICOS subcomplex [51]. We therefore postulated that CHCHD3 silencing would be sufficient to reproduce the cristae formation defects observed in PD-1-stimulated cells. CHCHD3 silencing indeed recapitulated several of the PD-1-induced dysfunctions in $\mathrm{CD}^{+} \mathrm{T}$ cells, such as the decline in mitochondrial depolarization and the reduction in IFNY production. Given the low transduction efficiency of the siRNA, however, we were unable to assess morphological alterations in mitochondrial cristae of $\mathrm{CHCHD} 3$ silenced $\mathrm{CD}^{+} \mathrm{T}$ cells in our system. CHCHD3 silencing in HeLa cells nonetheless leads to notable changes in cristae morphology and even to their loss in most cells [51].

The presence of RCS has been demonstrated in many tissues and cells, including T cells [39]. These RCS place individual complexes together, which increases electron transfer efficiency in the respiratory chain and reduces ROS production. The primary function of MICOS is to stabilize, position, and control the copy number of 
cristae junctions to organize the inner membrane into an efficient respiratory machine [51]. Indeed, cristae remodeling by OPA1 depletion affects RCS formation and decreases respiratory efficiency [38]. We anticipated that the reduction in OCR and $\triangle \Psi \mathrm{m}$ in addition to the dysmorphic cristae in $\mathrm{T}_{\mathrm{ACT}}+\mathrm{PD}$ cells might be linked to impaired RCS formation. BN-PAGE analyses nevertheless showed that complex I- and III-containing RCS were increased in $\mathrm{T}_{\mathrm{ACT}}+\mathrm{PD1}$ compared with $\mathrm{T}_{\mathrm{ACT}}$ cells. RCS were also increased in $\mathrm{T}_{\text {CTRL }}$ compared with $\mathrm{T}_{\mathrm{ACT}}$ cells, although cristae were also defective in $\mathrm{T}_{\mathrm{CTRL}}$ cells. The increased RCS assembly in $\mathrm{T}_{\mathrm{ACT}+\mathrm{PD} 1}$ and $\mathrm{T}_{\mathrm{CTRL}}$ cells might be a compensatory mechanism to guarantee mitochondrial respiration following severe ultrastructural disorganization of the inner membrane. The reduced complex-I-containing RCS assembly in $\mathrm{T}_{\mathrm{ACT}}$ cells could be related to upregulation of the co-chaperone $\mathrm{MCJ} / \mathrm{DnaJC15}$, a negative regulator of RCS levels in cardiomyocytes and $\mathrm{CD} 8^{+} \mathrm{T}$ lymphocytes [39].

\section{Conclusions}

Several studies underlined the importance of metabolic sufficiency in the initiation and maintenance of antitumor immunity $[15,44]$, and chemicals that enhance mitochondrial metabolism synergize with PD-1 blockade therapy to reduce tumor growth in mice [18]. Our studies highlight mitochondria as the main targets of PD-1 inhibitory activity, causing metabolic rewiring to FAO as well as apparently irreversible mitochondrial dysfunctions that are not simply the consequence of inhibition of the $\mathrm{T}$ cell activation program. We also found that structural alterations of the cristae network in PD-1engaged or resting $\mathrm{T}$ cells unexpectedly triggered RCS formation. A major challenge will be to design strategies to restore the function of these newly identified elements downstream of PD-1 to reinvigorate anti-tumor immune responses in vivo.

\section{Additional files}

Additional file 1: Supplementary Methods. Detailed description of the methods and materials used in the study. (DOCX $34 \mathrm{~kb}$ )

Additional file 2: Table S1. List of primers used for RT-qPCR analyses. (PDF $44 \mathrm{~kb}$ )

Additional file 3: Figure S1. Dose-dependent inhibition of T cell activation by PD-L1. (PDF $161 \mathrm{~kb}$ )

Additional file 4: Figure S2. MA-plots for differential expression analysis. (PDF $3199 \mathrm{~kb}$ )

Additional file 5: Table S2. Top 20 genes with the most divergent expression in the LRT model. (PDF $89 \mathrm{~kb}$ )

Additional file 6: Table S3. Pathways significantly enriched in the 578 genes selected. (PDF $56 \mathrm{~kb})$

Additional file 7: Figure S3. Scheme showing the metabolic pathways altered in PD-1-stimulated cells. (PDF 2970 kb)
Additional file 8: Figure S4. GO enrichment analysis for molecular function terms. (PDF $776 \mathrm{~kb}$ )

Additional file 9: Figure S5. GO enrichment analysis for biological processes terms. (PDF $777 \mathrm{~kb}$ )

Additional file 10: Figure S6. GO enrichment analysis for cellular components terms. (PDF $330 \mathrm{~kb}$ )

Additional file 11: Figure S7. ClueGO plot of the 84 mitochondrial genes differentially expressed after PD-1 ligation. (PDF $560 \mathrm{~kb}$ )

Additional file 12: Table S4. List of genes that partition or associate with mitochondria. (PDF $94 \mathrm{~kb}$ )

Additional file 13: Table S5. GO enrichment analysis of profile B by STEM (top 20). (PDF $84 \mathrm{~kb}$ )

Additional file 14: Figure S8. Changes in mitochondria-related gene expression is PD-L1 dose-dependent. (PDF $166 \mathrm{~kb}$ )

Additional file 15: Figure S9. Mitochondrial morphology analyzed by TEM. (PDF $5455 \mathrm{~kb}$ )

\section{Abbreviations}

ATP: Adenosine triphosphate; DMEM: Dulbecco's Modified Eagle Medium; DNA: Deoxyribonucleic acid; DNP: 2,4-dinitrophenol; ECAR: Extracellular acidification rate; ERK: Extracellular signal-regulated kinase; FAO: Fatty acid oxidation; FCCP: Carbonyl cyanide-4-(trifluoromethoxy) phenylhydrazone; GO: Gene ontology; HEK: Human embryonic kidney; IFNy: Interferon-gamma; ITIM: Immunoreceptor tyrosine-based inhibition motif; ITSM: Immunoreceptor tyrosine-based switch motif;"; KEGG: Kyoto encyclopedia of genes and genomes; LRT: Likelihood ratio test; MIB: Mitochondrial intermembrane space bridging; MICOS: Mitochondrial contact site and cristae organizing system; mtDNA: Mitochondrial DNA; mTOR: Mammalian target of rapamycin; OCR: Oxygen consumption rate; OXPHOS: Oxidative phosphorylation; PCR: Polymerase chain reaction; PD-1: Programmed death-1; PDL1: Programmed death-ligand 1; PD-L2: Programmed death-ligand 2; PTEN: Phosphatase and tensin homolog; RCS: Respiratory chain supercomplexes; RNA: Ribonucleic acid; RNA-Seq: RNA sequencing; ROS: Reactive oxygen species; SHP-1: Src homology region 2 domaincontaining phosphatase-1; SHP-2: Src homology region 2 domain-containing phosphatase-2; SRC: Spare respiratory capacity; STEM: Short time-series expression miner; TCR: T cell receptor; TEM: Transmission electron microscopy; TIL: Tumor-infiltrating lymphocytes; TMRM: Tetramethylrhodamine, methyl ester

\section{Acknowledgments}

We thank R.M. Peregil (technical assistance), M.C. Moreno and S. Escudero (flow cytometry service), C. Patiño (electron microscopy service) and S. Gutiérrez-Erlandsson (advanced light microscopy service) for technical help, M. Gómez de Cedrón (IMDEA Alimentación) for her outstanding support in FAO assays, and C Mark for excellent editorial assistance.

\section{Authors' contributions}

S.M. conceived the study. A.E.-C., S.H. and M.G. generated RNA libraries and RNA-seq processing and analysis, M.E.S. and A.G.P. carried out bioinformatic analyses, C.N. performed blue native experiments, J.O., R.A.L. and J.S. designed and performed most of the experiments. J.M.C., J.O., R.A.L. and S.M. interpreted experimental data, S.M. wrote the manuscript. All authors read and discussed the manuscript.

\section{Funding}

This work was funded by grants from the Spanish Ministerio de Economía y Competitividad (MINECO) (SAF2014-54475-R and SAF2017-83732-R to SM; SAF2016-75916-R to JMC; AEI/FEDER, EU), the Instituto de Salud Carlos III (PT17 PT17/0009/0019, AEI/FEDER, EU), the Comunidad de Madrid (B2017/ BMD-3733; Inmunothercan-CM, to SM), and the Merck-Salud Foundation (to SM). JO, JS and CN-T are supported by predoctoral fellowships from the MINECO and the EU European Social Fund.

\section{Availability of data and materials}

The RNA-seq datasets generated during the current study are available in the GEO repository, accession number GSE122149. Other data and materials are available from the corresponding author upon reasonable request. 


\section{Ethics approval and consent to participate}

Blood samples were from the Comunidad de Madrid Blood Transfusion Center (Madrid, Spain), obtained with appropriate informed consent from the donors. No personal data were registered and all procedures with these cells were in accordance with the ethical standards and approved by the Ethics Committees of the CNB-CBMSO (ref. 2014-0007) and of the Spanish Research Council.

\section{Consent for publication}

We confirm that the manuscript has been read and approved by all named authors and that there are no other persons who satisfied the criteria for authorship but are not listed. We further confirm that the order of authors listed in the manuscript has been approved by all of us. We confirm that we have given due consideration to the protection of intellectual property associated with this work and that there are no impediments to publication, including the timing of publication, with respect to intellectual property. In so doing we confirm that we have followed the regulations of our institutions concerning intellectual property.

\section{Competing interests}

The authors declare that they have no competing interest.

\section{Author details}

'Department of Immunology and Oncology, Centro Nacional de Biotecnología (CNB/CSIC), Madrid, Spain. ${ }^{2}$ Centro Andaluz de Estudios Bioinformáticos (CAEBi), Seville, Spain. ${ }^{3}$ Centro de Biología Molecular-Severo Ochoa (CBMSO/CSIC) and Centro de Investigación Biomédica en Red de Enfermedades Raras (CIBERER-ISCIII), Universidad Autónoma de Madrid, Madrid, Spain. ${ }^{4}$ CNAG-CRG, Centre for Genomic Regulation, Barcelona and Institute of Science and Technology (BIST), Barcelona, Spain. ${ }^{5}$ Universitat Pompeu Fabra, Barcelona, Spain.

\section{Received: 12 November 2018 Accepted: 24 May 2019}

\section{Published online: 13 June 2019}

\section{References}

1. Francisco LM, Sage PT, Sharpe AH. The PD-1 pathway in tolerance and autoimmunity. Immunol Rev. 2010;236:219-42.

2. Probst HC, McCoy K, Okazaki T, Honjo T, van den Broek M. Resting dendritic cells induce peripheral CD8+ T cell tolerance through PD-1 and CTLA-4. Nat Immunol. 2005;6(3):280-6.

3. Pauken $\mathrm{KE}$, Wherry EJ. Overcoming $T$ cell exhaustion in infection and cancer. Trends Immunol. 2015;36(4):265-76.

4. Kansy BA, Concha-Benavente F, Srivastava RM, Jie HB, Shayan G, Lei Y, et al. PD-1 status in CD8(+) T cells associates with survival and anti-PD-1 therapeutic outcomes in head and neck cancer. Cancer Res. 2017:77(22):6353-64.

5. Topalian SL, Drake CG, Pardoll DM. Immune checkpoint blockade: a common denominator approach to cancer therapy. Cancer Cell. 2015;27(4):450-61.

6. Okazaki T, Maeda A, Nishimura H, Kurosaki T, Honjo T. PD-1 immunoreceptor inhibits B cell receptor-mediated signaling by recruiting src homology 2-domain-containing tyrosine phosphatase 2 to phosphotyrosine. Proc Natl Acad Sci U S A. 2001;98(24):13866-71.

7. Yokosuka T, Takamatsu M, Kobayashi-Imanishi W, Hashimoto-Tane A, Azuma M, Saito T. Programmed cell death 1 forms negative costimulatory microclusters that directly inhibit T cell receptor signaling by recruiting phosphatase SHP2. J Exp Med. 2012;209(6):1201-17.

8. Gadina M, Stancato LM, Bacon CM, Larner AC, O'Shea JJ. Involvement of SHP-2 in multiple aspects of IL-2 signaling: evidence for a positive regulatory role. J Immunol. 1998;160(10):4657-61.

9. Lacalle RA, Mira E, Gomez-Mouton C, Jimenez-Baranda S, Martínez-A. C, Mañes S. Specific SHP-2 partitioning in raft domains triggers integrinmediated signaling via Rho activation. J Cell Biol. 2002;157(2):277-89.

10. Salmond RJ, Huyer G, Kotsoni A, Clements L, Alexander DR. The src homology 2 domain-containing tyrosine phosphatase 2 regulates primary T-dependent immune responses and Th cell differentiation. J Immunol. 2005:175(10):6498-508

11. Nguyen TV, Ke Y, Zhang EE, Feng GS. Conditional deletion of Shp2 tyrosine phosphatase in thymocytes suppresses both pre-TCR and TCR signals. J Immunol. 2006;177(9):5990-6.
12. Rota G, Niogret C, Dang AT, Barros CR, Fonta NP, Alfei F, et al. Shp-2 is dispensable for establishing $T$ cell exhaustion and for PD-1 signaling in vivo. Cell Rep. 2018;23(1):39-49.

13. Pearce EL, Walsh MC, Cejas PJ, Harms GM, Shen H, Wang LS, et al. Enhancing CD8 T-cell memory by modulating fatty acid metabolism. Nature. 2009:460(7251):103-7.

14. van der Windt GJ, Everts B, Chang CH, Curtis JD, Freitas TC, Amiel E, et al. Mitochondrial respiratory capacity is a critical regulator of CD8+ T cell memory development. Immunity. 2012;36(1):68-78.

15. Scharping NE, Menk AV, Moreci RS, Whetstone RD, Dadey RE, Watkins SC, et al. The tumor microenvironment represses $T$ cell mitochondrial biogenesis to drive intratumoral T cell metabolic insufficiency and dysfunction. Immunity. 2016;45(2):374-88.

16. Patsoukis N, Bardhan K, Chatterjee P, Sari D, Liu B, Bell LN, et al. PD-1 alters T-cell metabolic reprogramming by inhibiting glycolysis and promoting lipolysis and fatty acid oxidation. Nat Commun. 2015;6:6692.

17. Bengsch $B$, Johnson AL, Kurachi M, Odorizzi PM, Pauken KE, Attanasio J, et al. Bioenergetic insufficiencies due to metabolic alterations regulated by the inhibitory receptor PD-1 are an early driver of CD8(+) T cell exhaustion. Immunity. 2016;45(2):358-73.

18. Chamoto K, Chowdhury PS, Kumar A, Sonomura K, Matsuda F, Fagarasan S, et al. Mitochondrial activation chemicals synergize with surface receptor PD 1 blockade for T cell-dependent antitumor activity. Proc Natl Acad Sci U S A. 2017;114(5):E761-E70.

19. Thommen DS, Koelzer VH, Herzig P, Roller A, Trefny M, Dimeloe S, et al. A transcriptionally and functionally distinct PD-1(+) CD8(+) T cell pool with predictive potential in non-small-cell lung cancer treated with PD-1 blockade. Nat Med. 2018;24(7):994-1004.

20. Patsoukis N, Li L, Sari D, Petkova V, Boussiotis VA. PD-1 increases PTEN phosphatase activity while decreasing PTEN protein stability by inhibiting casein kinase 2. Mol Cell Biol. 2013;33(16):3091-8.

21. Marco-Sola S, Sammeth M, Guigo R, Ribeca P. The GEM mapper: fast, accurate and versatile alignment by filtration. Nat Methods. 2012;9(12):1185-8.

22. Love Ml, Huber W, Anders S. Moderated estimation of fold change and dispersion for RNA-seq data with DESeq2. Genome Biol. 2014;15(12):550.

23. Ernst J, Bar-Joseph Z. STEM: a tool for the analysis of short time series gene expression data. BMC Bioinformatics. 2006;7:191.

24. Acebo P, Giner D, Calvo P, Blanco-Rivero A, Ortega AD, Fernandez PL, et al. Cancer abolishes the tissue type-specific differences in the phenotype of energetic metabolism. Transl Oncol. 2009;2(3):138-45.

25. Venegas $V$, Halberg MC. Measurement of mitochondrial DNA copy number. Methods Mol Biol. 2012:837:327-35.

26. Dagda RK, Cherra SJ 3rd, Kulich SM, Tandon A, Park D, Chu CT. Loss of PINK1 function promotes mitophagy through effects on oxidative stress and mitochondrial fission. J Biol Chem. 2009:284(20):13843-55.

27. Chang CH, Curtis JD, Maggi LB Jr, Faubert B, Villarino AV, O'Sullivan D, et al. Posttranscriptional control of T cell effector function by aerobic glycolysis. Cell. 2013;153(6):1239-51.

28. Monticone M, Panfoli I, Ravera S, Puglisi R, Jiang MM, Morello R, et al. The nuclear genes Mtfr1 and Dufd1 regulate mitochondrial dynamic and cellular respiration. J Cell Physiol. 2010:225(3):767-76.

29. Campello S, Lacalle RA, Bettella M, Mañes S, Scorrano L, Viola A. Orchestration of lymphocyte chemotaxis by mitochondrial dynamics. J Exp Med. 2006;203(13):2879-86

30. van der Laan M, Horvath SE, Pfanner N. Mitochondrial contact site and cristae organizing system. Curr Opin Cell Biol. 2016;41:33-42.

31. Schägger $\mathrm{H}$, Pfeiffer $\mathrm{K}$. Supercomplexes in the respiratory chains of yeast and mammalian mitochondria. EMBO J. 2000:19(8):1777-83.

32. Enriquez JA. Supramolecular organization of respiratory complexes. Annu Rev Physiol. 2016;78:533-61.

33. Acin-Perez R, Fernandez-Silva P, Peleato ML, Perez-Martos A, Enriquez JA. Respiratory active mitochondrial supercomplexes. Mol Cell. 2008; 32(4):529-39.

34. Gu J, Wu M, Guo R, Yan K, Lei J, Gao N, et al. The architecture of the mammalian respirasome. Nature. 2016;537(7622):639-43.

35. Letts JA, Fiedorczuk K, Sazanov LA. The architecture of respiratory supercomplexes. Nature. 2016;537(7622):644-8.

36. Sousa JS, Mills DJ, Vonck J, Kuhlbrandt W. Functional asymmetry and electron flow in the bovine respirasome. Elife. 2016;5:e21290.

37. Wu M, Gu J, Guo R, Huang Y, Yang M. Structure of Mammalian Respiratory Supercomplex I1IIIIV1. Cell. 2016;167(6):1598-609 e10. 
38. Cogliati S, Frezza C, Soriano ME, Varanita T, Quintana-Cabrera R, Corrado M, et al. Mitochondrial cristae shape determines respiratory chain supercomplexes assembly and respiratory efficiency. Cell. 2013;155(1):160-71.

39. Champagne DP, Hatle KM, Fortner KA, D'Alessandro A, Thornton TM, Yang $R$, et al. Fine-tuning of $C D 8(+) T$ cell mitochondrial metabolism by the respiratory chain repressor $\mathrm{MCJ}$ dictates protection to influenza virus. Immunity. 2016;44(6):1299-311.

40. Wherry EJ, Ha SJ, Kaech SM, Haining WN, Sarkar S, Kalia V, et al. Molecular signature of CD8+ T cell exhaustion during chronic viral infection. Immunity. 2007;27(4):670-84.

41. Doering TA, Crawford A, Angelosanto JM, Paley MA, Ziegler CG, Wherry EJ. Network analysis reveals centrally connected genes and pathways involved in CD8+ T cell exhaustion versus memory. Immunity. 2012;37(6):1130-44.

42. Schietinger A, Philip M, Krisnawan VE, Chiu EY, Delrow JJ, Basom RS, et al. Tumor-specific T cell dysfunction is a dynamic antigen-driven differentiation program initiated early during tumorigenesis. Immunity. 2016;45(2):389-401.

43. Fuller MJ, Khanolkar A, Tebo AE, Zajac AJ. Maintenance, loss, and resurgence of T cell responses during acute, protracted, and chronic viral infections. J Immunol. 2004;172(7):4204-14.

44. Patsoukis N, Weaver JD, Strauss L, Herbel C, Seth P, Boussiotis VA. Immunometabolic regulations mediated by coinhibitory receptors and their impact on T cell immune responses. Front Immunol. 2017:8:330.

45. Papa S, De Rasmo D, Scacco S, Signorile A, Technikova-Dobrova Z, Palmisano G, et al. Mammalian complex l: a regulable and vulnerable pacemaker in mitochondrial respiratory function. Biochim Biophys Acta. 2008:1777(7-8):719-28

46. Acin-Perez R, Gatti DL, Bai Y, Manfredi G. Protein phosphorylation and prevention of cytochrome oxidase inhibition by ATP: coupled mechanisms of energy metabolism regulation. Cell Metab. 2011;13(6):712-9.

47. Di Benedetto G, Scalzotto E, Mongillo M, Pozzan T. Mitochondrial Ca (2)(+) uptake induces cyclic AMP generation in the matrix and modulates organelle ATP levels. Cell Metab. 2013;17(6):965-75.

48. Buck MD, O'Sullivan D, Klein Geltink Rl, Curtis JD, Chang CH, Sanin DE, et al. Mitochondrial dynamics controls T cell fate through metabolic programming. Cell. 2016;166(1):63-76.

49. Teijeira A, Labiano S, Garasa S, Etxeberria I, Santamaria E, Rouzaut A, et al. Mitochondrial morphological and functional reprogramming Ffollowing CD137 (4-1BB) costimulation. Cancer Immunol Res. 2018;6(7):798-811.

50. Ghoneim HE, Fan Y, Moustaki A, Abdelsamed HA, Dash P, Dogra P, et al. De Novo epigenetic programs inhibit PD-1 blockade-mediated T cell rejuvenation. Cell. 2017;170(1):142-57 e19.

51. Friedman JR, Mourier A, Yamada J, McCaffery JM, Nunnari J. MICOS coordinates with respiratory complexes and lipids to establish mitochondrial inner membrane architecture. Elife. 2015:4:e07739.

\section{Publisher's Note}

Springer Nature remains neutral with regard to jurisdictional claims in published maps and institutional affiliations.

Ready to submit your research? Choose BMC and benefit from:

- fast, convenient online submission

- thorough peer review by experienced researchers in your field

- rapid publication on acceptance

- support for research data, including large and complex data types

- gold Open Access which fosters wider collaboration and increased citations

- maximum visibility for your research: over $100 \mathrm{M}$ website views per year

At $\mathrm{BMC}$, research is always in progress.

Learn more biomedcentral.com/submissions 